\author{
MARTIN NEIL BAILY \\ University of Maryland \\ and McKinsey Global Institute
}

\title{
Competition, Regulation, and Efficiency in Service Industries
}

IN THIS PAPER I examine the regulatory and competitive environments in which four service industries operate in Europe and Japan, suggesting how certain types of regulation and the lack of adequate competition reduce productivity. I then present estimates of the relative productivities of these industries compared with the United States and suggest that in practice, the differences in the competitive environments of these countries have led to differences in the productivities of the industries.

Service sector productivity is important. To some observers the international competitiveness of a country depends solely on the performance of its manufacturing sector. But when the productivity of the United States is compared with that of other countries, the service sector is even more important, because it accounts for a much larger share of output and employment than does manufacturing.

Understanding why productivity differences across countries exist in a given industry can reveal policy changes that could enhance economic performance or can strengthen the case for policy changes that have al-

This study was supported in part by a grant from the Sloan Foundation to the Brookings Institution. Kacy Collins provided excellent and essential research assistance. The productivity comparisons reported here rely on the study of service sector productivity directed by William Lewis of the McKinsey Global Institute. I have benefited from comments made on earlier versions of this paper at seminars at the University of Maryland, Resources for the Future, and the University of Rochester and by Barry Bosworth, Clifford Winston, and others at Brookings. Tom Jansen of McKinsey shared his own work on service sector restrictions with me and provided many useful sources and comments. 
ready been proposed. For example, economic theory has stressed the social cost of the increased price and reduction in output that result when competition in an industry is inadequate. Based on this theory, economists have long advocated competition and deregulation. But the comparisons reported here indicate that certain types of regulation lead to substantial inefficiencies in production and distortions in the natural evolution of industries. Competition that is restricted or regulated can prevent the most efficient producers from entering an industry or from expanding. It can slow the diffusion of innovations and allow managers to operate with excess labor, even relative to the given technology-it leads to slack in enterprises. The effects of anticompetitive policies may be greater than has been generally realized.

To illustrate this observation, I point to a recent study that argued that the potential benefits of deregulating European airlines would be smaller than those achieved in the United States because of the structure of the European industry, which has smaller airlines, fewer passengers, and a different route structure from the U.S. industry. ${ }^{1}$ Although granting some effects from differences in geography, I would argue, based on the comparison of productivity in airlines reported below, that all of these industry characteristics will change, probably drastically, if European airlines are deregulated and that the potential productivity gains will be very large.

Another advantage of productivity comparisons is that they can affect the way the degree of competitive intensity in an industry is judged. This is often done by looking at the number of companies in an industry or at the market shares of the largest companies. In some situations, however, such measures can be inadequate. The case studies suggest that regulatory policies that prevent the exit of small companies have been a major obstacle to industry evolution and productivity increase in several countries. In the service industries studied here, there are too many small retailers in several countries, too many small airlines in Europe, and too many small banks in Germany and the United States.

Competition may be inadequate in other situations as well. For example, although several companies may compete with each other at home, the industry may not be competititve in international markets if it does not have the most productive technologies. Competitive policies toward service industries should allow or even encourage direct foreign investment. 
This paper does not argue that the U.S. economic institutions ensure fully competitive markets. There are many examples of inefficient regulation within the U.S. economy, imperfectly implemented deregulation, industries with weak competition, and regulation that is costly in productivity terms even if justified for other reasons. ${ }^{2}$ Nor do I argue that all regulation is harmful to productivity - antitrust regulation, if used appropriately, can enhance competition; patent laws promote innovation; securities laws protect property rights, and other examples can be found. But, in general, service industries in the United States are more subject to private control, more exposed to market forces, and regulated in ways that promote productivity increase more effectively than is the case in other countries.

\section{Regulations and Restrictions in Specific Industries}

I review the salient economic factors affecting four major service industries-airlines, retail banking, telecommunications, and general merchandise retailing -in France, Germany, Japan, the United Kingdom, and the United States. Not all countries were studied for all industries. ${ }^{3}$

I do not review regulations in the United States because I assume that the U.S. regulatory environment is well known to the readers of this journal, but I do try to bring out aspects of regulation overseas that differ from U.S. regulations and that are likely to affect productivity.

\section{Restrictions on Airlines in Europe}

The countries of Europe are small compared with the United States, and each has a well-developed railroad system that carries much of its domestic passenger and freight transportation. ${ }^{4}$ Consequently, the bulk of air travel provided by European airlines is international and is sub-

2. For example, I argue that the United States now lags behind Japan in encouraging competition in regional telephone service.

3. The McKinsey study also covered restaurants; it concluded that the industry was very competitive in all three of the countries studied and found little difference in productivity among them. I do not examine the restaurant industry study.

4. This section draws on Kasper (1988); O'Connor (1971); Bailey, Graham, and Kaplan (1985); Brown (1987); Caves and others (1987); OECD (1988); Straszheim (1969); Gordon (1992); Morrison and Winston (1985 and 1986); Economist (1986); and Evans and Kessides (1993). 
ject to regulations that have developed to cover international travel. ${ }^{5}$

Because the United States and the countries of Europe have never been able to agree on a comprehensive system of regulation for international air travel, the regulatory system is a mixture of bilateral and multilateral agreements that have grown up since the 1940s. The Chicago Conference on International Civil Aviation, held in 1944, led to the creation of the International Civil Aviation Organization (ICAO). This organization established the first legal principles for international aviation, such as sovereignty over airspace and safety regulations.

The Chicago conference also produced the International Air Services Transit Agreement, which allows scheduled airlines to transit foreign airspace and make technical stops in other countries. The United States proposed a more extensive agreement, the International Air Transport Agreement, under which international airlines would have had more liberal access to air routes. The United Kingdom, joined by many other countries, opposed this proposal, largely out of concern that U.S. airlines would dominate the international industry. The United States stopped pressing for the agreement after Pan American Airlines dropped its support. The Bermuda agreement of 1946 basically left it to countries to negotiate fares and other conditions through bilateral agreements.

In the absence of an open multilateral agreement, the International Air Transport Association (IATA) developed as a form of self-regulation of international airline competition. (ICAO has been largely restricted to technical and safety issues.) IATA set prices, procedures for connecting flights and for sharing ticket revenues, and accreditation of travel agents. As well as a surrogate for government agreements, IATA has served as a trade association for the airlines and a way for them to negotiate bilaterally in setting fares and conditions on international routes. The United States routinely approved IATA fares until the deregulation movement started in the 1970 s. International passenger transportation has been subject to managed trade.

IATA's ability to control fares on the North Atlantic route has broken down, but elsewhere, the association remains a potent force. Most existing air service agreements are collusive duopolies, under what are called "Bermuda I standard form air service agreements."

5. Even within the European countries, air travel has been regulated to protect the railroads from competition. 
Under Bermuda I agreements, airlines are not free to enter markets where they see profit opportunities. An airline must first be chosen by its government to provide scheduled service on the route from one city in its own country to a specific city in another country; the government of the other country then chooses its own airline to provide matching service. Under some agreements more than one airline is selected by each country, but single airline arrangements are the usual case except for agreements with the United States. Most agreements restrict entry for charter services and air cargo. Countries that allow charter flights often restrict their activities to prevent direct competition with the scheduled carriers.

Before the European Community (EC) embarked on its single-market program, some 200 bilateral agreements among twenty-two countries governed international air service in Europe. Carriers were effectively prohibited from offering service between two other European countries (so-called fifth freedom rights). Of some 400 routes within the EC, only 44 allow such rights, and only about 20 had competition between more than one airline per country in 1987 . In several cases, the two designated carriers on a city pair route split the revenues $50-50 .^{6}$

The bilateral agreements generally restrict the number of seats that can be offered, and some restrict cargo capacity. These restrictions usually do not apply to U.S. routes, but until the recent changes in Europe, they were standard practice elsewhere.

As a deregulated airline industry has emerged within the United States, the importance of unrestricted access to different routes has become clear. The airline industry has network externalities, that is, the ability of an airline to compete effectively on one route depends on the extent or nature of its service on other routes. The system of bilateral agreements has sharply limited the ability of European airlines to optimize route networks. In particular, only two European airlines have established the hub and spoke system that has developed in the domestic U.S. market. ${ }^{7}$

6. Commission of the European Communities (1988).

7. British Airways in London and KLM in Amsterdam are establishing hub and spoke operations. This system provides substantial benefits to consumers but may create congestion and hence productivity problems for the airlines. This point is discussed later in the paper. 
Different procedures are used to set prices depending on the countries and routes involved. The standard Bermuda I agreement involves double approval of any rate set-either country can reject a proposed rate reduction, and in practice rates are then set to give the high-cost airline an adequate rate of return. Not all bilateral agreements are this restrictive. Double disapproval allows greater competition because both parties must disapprove a fare change. Of course, even here the competition is usually between only two airlines, providing ample motivation for strategic pricing rather than real competition. Even with double disapproval, rates are often set within a zone, precluding predatory pricing intended to drive one airline out of the market.

Air cargo has also been subject to price regulation, but in practice this has broken down in Europe. Many shippers are insensitive to the exact route of their freight and can truck cargo to competing locations in the European market, rather than ship it by air. Entry restrictions are used in the cargo market, however. The United Kingdom has refused all-cargo airlines access to Heathrow airport, and Germany has restricted ground handling of cargo at Frankfurt.

Unions have countervailing effects on productivity, according to Richard Freeman and James Medoff. Unions foster efficiency by reducing turnover and encouraging professional management, but they may also impose restrictive work-rules and resist change and layoffs. ${ }^{8}$ In the airline industry, union rules have been an obstacle to productive operations in both the United States and Europe. In the United States, however, entry and competition from nonunion airlines or, in the case of the weaker airlines, the threat of bankruptcy has forced the unions to modify their work practices. In Europe airline workers are relatively highly paid, and the unions are strong. Managers thus find it difficult to adopt the most efficient methods of operation and, if they succeeded in raising productivity, would have a hard time laying off workers.

One reason why European governments have been reluctant to promote competition among airlines is that there are government-owned, national flag carriers in many of the European countries. Aside from British Airways, which was privatized in the 1980s, the main European carriers have substantial government ownership, as figure 1 shows. This has not only discouraged deregulation, but also provided a financial

8. Freeman and Medoff (1984). 
Figure 1. State Ownership of Major European Airlines

Percent

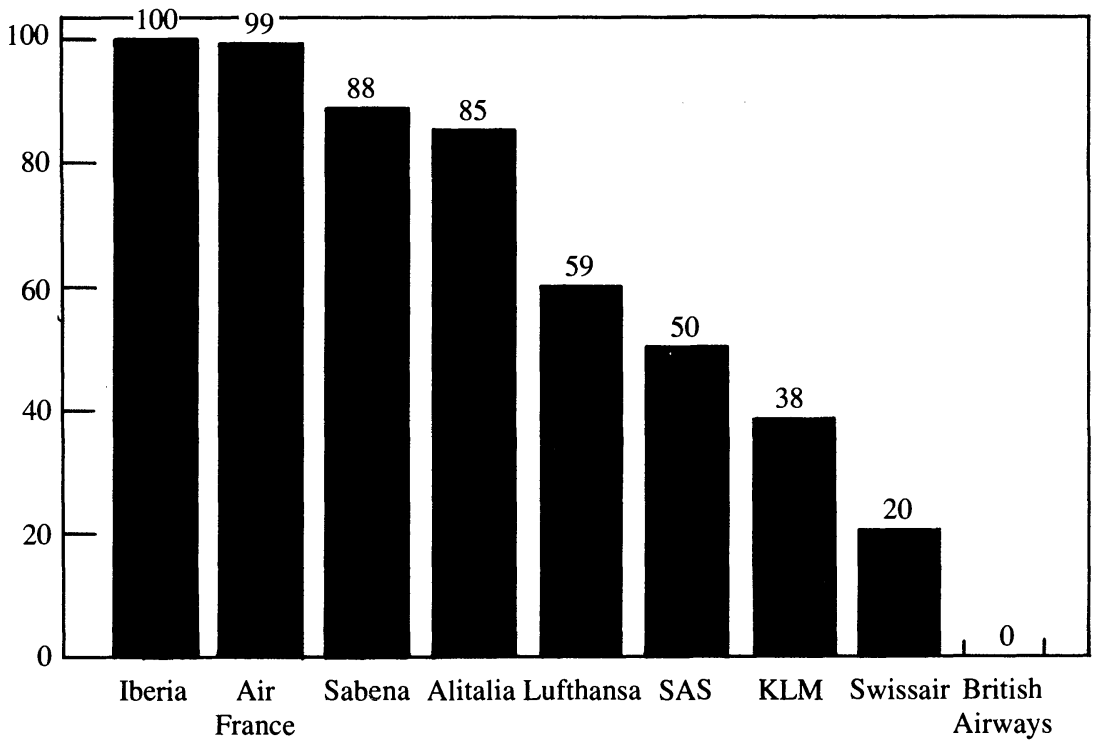

Source: The Economist, August 25, 1984; reprinted in McKinsey Global Institute (1992).

cushion for these airlines, with government support used to bail out carriers that operate inefficiently and thereby incur losses or fail to earn an adequate return on capital.

\section{Banking in Germany and the United Kingdom}

The EC commission that studied the potential effects of the 1992 European integration argued in 1988 that the substantial restrictions on competition in the EC countries were resulting in higher prices to customers than those that could be obtained within a competitive market. ${ }^{9}$ A Price-Waterhouse study for the EC estimated that the price of banking services would drop 33 percent in Germany and 18 percent in the United Kingdom if the European single market were completed. ${ }^{10}$ The nature

9. This section draws on Dziobek (1992); Baltensperger and Dermine (1987); Berger and Humphrey (1992); Fixler and Zieschang (1992); Dale (1982 and 1984); OECD (1978 and 1992a); Straetz (1993); U.S. Office of Technology Assessment (1987); and Cumming and Sweet (1987).

10. Commission of the European Communities (1988, p. 91, table 5.1.4). 
Table 1. Market Shares of German Bank Groups, 1970-92

Percent of total assets at year-end unless noted.

\begin{tabular}{lrccc}
\hline Bank group & 1970 & 1978 & 1988 & 1992 (July) \\
\hline Commercial banks & 24.9 & 25.1 & 23.6 & 26.1 \\
(Big three banks) $^{\text {Private mortgage }}$ a & $(10.2)$ & $(10.6)$ & $(8.9)$ & $(9.5)$ \\
Total, private group & 6.6 & 8.3 & 9.0 & 9.0 \\
State banks & 31.5 & 33.4 & 34.6 & 35.1 \\
State mortgage & 38.5 & 38.2 & 37.3 & 36.1 \\
Total, state group & 7.1 & 4.8 & 4.9 & 2.4 \\
Cooperative group & 45.6 & 43.0 & 42.2 & 38.5 \\
Special banks & 11.5 & 14.3 & 16.9 & 14.8 \\
Postal & 8.4 & 6.2 & 6.7 & 11.8 \\
Total & 1.9 & 1.9 & 1.5 & - \\
\hline
\end{tabular}

Source: Dziobek (1992)

a. Includes cooperative mortgage banks.

b. Included in the state group in 1992 .

of the restrictions on competition derive from the regulated structure of the industry in all cases. Since the turmoil of the interwar years, most countries have regarded financial stability as more important than competitive efficiency.

The banking industry in Germany is composed of private commercial banks, which had 23.6 percent of bank assets in 1988; private and cooperative mortgage lenders, with 9 percent; state banks and mortgage lenders, with 42.2 percent; co-ops, with 16.9 percent; and special banks, with 6.7 percent. The special banks are both state and private and exist to serve the other banks. Table 1 shows the market shares for different years.

The banks in a given group belong to networks of regional federal bank associations, and these associations supervise the operations of their members and provide services such as deposit insurance. They represent their members in meetings with other bank groups and provide a link to the Bundesbank. These networks also act to limit excess competition. The three biggest private banks operate somewhat differently. They are not connected in the same way with their bank groups, and they do compete against each other to a limited extent. They cooperate, however, to operate the payments clearing system, for deposit insurance, and in deciding on bank regulation. The private commercial banks also operate the private mortgage banks as subsidiaries. 
The system of bank groups was created in Germany as a matter of policy. The allies broke the financial cartels after World War II, and new bank policy was based on the idea of "socially responsible free markets." The prevailing ideology held that government should take an active role in competition policy and in structuring markets. The bank group system was considered an important part of this program, a way to combine competition with stability: one bank team would compete against another, but competition among members of the same team would be limited. Because the bank groups are organized around geographic regions, however, the team system meant that there was not much competition overall. The banking authorities viewed this lack of competition as appropriate. The Bundesbank considered "cutthroat competition" among banks, and specifically competition by offering higher interest rates or lower bank fees, to be a threat to financial stability, a position that it still holds today. The German antitrust or cartel laws explicitly allow bank associations to share information on interest rates, fees, and commissions.

In the United States the development of money market mutual funds, which offered checkwriting capabilities with market interest rates, was instrumental in forcing bank deregulation and increased competition. Germany has not allowed the emergence of such competition from nonbank financial intermediaries. Because of universal banking, there are no effective outsiders in the German market.

Local laws also restrict German banks. In some regions banks cannot lend out more than they have collected from local depositors, a restriction that makes it hard for a bank to expand into a new market. It cannot bring in funds; it must develop its network slowly by attracting deposits.

German and U.S. banks play different roles in their respective economies. Representatives of German banks sit on corporate boards, and vice versa. In fact, the banks often control the majority of the voting stock in an industrial corporation. Interlocking directorships make it difficult for companies to shop around for the best terms for their borrowing. Both for corporate borrowers and consumer depositors, a very strong brand loyalty reduces effective competition. In fact, several U.S. banks tried to compete in the German market in the 1980s, most without success. ${ }^{11}$ German depositors, having read about the turmoil in the U.S.

11. Citibank bought a branch network in Germany and is operating it successfully. 
banking industry, regarded U.S. banks as unsafe. And most of the potential business borrowers already had strong ties to existing German banks.

The U.K. BANK System. After World War II banks in the United Kingdom operated with an explicit and legal cartel that set interest rates on deposits in relation to the Bank of England's discount rate. This formal cartel was disbanded by request of the government in September 1971, and since then the formal regulatory environment has been less restrictive in the United Kingdom than in Germany. The degree of competition does not appear to be any greater, however. The main large banks, not the Bank of England, run the payments system, which gives them a legal forum in which to meet, exchange information, and potentially to collude. (In the United States the payment system is run by the Federal Reserve.) Retail banking in the United Kingdom is highly concentrated, with National Westminster, Barclay's, Lloyd's, and Midland banks dominating the market.

Even after the cartel was abolished in 1971, no aggressive policy to encourage competition in domestic retail banking was made, and so old patterns of bank behavior have continued. Although it is not an easy proposition to document fully, experts on the U.K. banking industry have referred to the "gentlemen's club" philosophy under which the system operates. If a bank customer goes across the street to another bank to open an account, it is said, then the two bank managers soon get on the phone to discuss what is wrong with the customer. An assessment of retail banking in several countries, made by the U.S. Office of Technology Assessment, aptly describes the U.K. case: "Particularly in countries with stable regulated markets, nominally competing banks have often been happy to fall into patterns of peaceful coexistence." 12

In a recent study of U.K. banks, Shelagh Heffernan demonstrates that although regulatory changes may have altered the nature of competition in British banking, individual banks are still " price makers,", and there is good evidence of price discrimination. ${ }^{13}$

PROBlemS IN U.S. BANKS. The regulation of banks and savings and loans (S\&Ls) in the United States can hardly be held up as a model of

12. Office of Technology Assessment (1987, p. 100).

13. Heffernan (forthcoming). 
success. Banks were heavily regulated in the early postwar period, with restrictions on both interstate banking and interest rates. Deregulation brought strong competition from nonbank financial intermediaries. Many S\&Ls were technically bankrupt by 1980 , with little to lose if they took further risks. They had access to low-cost deposit insurance, which allowed them to attract funds despite their precarious state, and bank supervision became rather lax. As a result, some banks and S\&Ls took on riskier and riskier portfolios, and then others were forced to follow in order to compete for deposits. Taxpayers have had to foot the bill for the subsequent defaults.

Despite this crisis, the U.S. regulatory environment has encouraged competition in the banking system. Facing competition both for deposits and for loans, U.S. banks have repeatedly cut operating costs to preserve the slim profit margins that they could obtain from the gap between borrowing and lending rates of interest.

Because of the restrictions on interstate banking, the U.S. banking industry has yet to achieve an industrial structure that minimizes costs. Further consolidations of small banks, with attendant efficiency gains, can be expected.

\section{Telecommunications}

The telecommunications industries in Europe and Japan have grown up with monopoly and state ownership. ${ }^{14}$ Monopoly, of course, was also the case in the United States until recently and remains the case for local service. Despite these similarities, there are important differences among the countries. The U.S. industry has always been private, and competition has been introduced into long-distance service. Japan and the United Kingdom have moved recently to privatize their industries and introduce competition into telephone service. Germany and France have retained a commitment to public ownership but have followed different technology strategies.

Telecommunications in JAPAN. From 1952 until 1985, Nippon Tel-

14. This section draws on Ergas (1992); Nambu, Suzuki, and Honda (1989); Crandall and Flamm, eds. (1989); Borrus and others (1985); Bolter, McConnaughey, and Kelsey (1990); Bortnick (1983), Gerus and Schott (1992); Hyman, Toole, and Avellis (1987); Davidson, Hubert, and St. Croix (1993); OECD (1992b); U.S. Department of Commerce (1991) (supplemented with memos from the Germany desk of the Department of Commerce); and Ypsilanti and Mansell (1987). 
egraph and Telephone (NTT), a publicly held corporation, monopolized domestic public common carrier telecommunications in Japan. International service was provided by Kokusai Denshin Denwa. These monopolies were based on the assumption that telecommunications was a natural monopoly because of the large economies of scale involved in providing service. This argument was taken from the debate in the United States, although the public ownership of NTT was based more on the European model.

In the United States the Federal Communications Commission (FCC) determined that there was no natural monopoly in intercity telecommunications and started to allow MCI to compete with AT\&T for longdistance service. In Japan the pressure for increased competition came from the business sector, where data transmission over telephone lines became increasingly important. In 1971 the Ministry of Post and Telephone began a gradual relaxation of the restrictions on business data transmissions. This freedom was extended to facsimile machines in 1972 , and in 1982 small- and medium-size businesses were allowed to provide data transmissions services to other small- and medium-size businesses or groups of such firms. ${ }^{15}$ Four companies immediately entered the market, but no others did because of the restriction on service. The restrictions were eased further in May 1983, and by April 1984 thirty-eight systems were in operation.

In 1985 the Telecommunications Business Law and the Nippon Telegraph and Telephone Corporation Law went into effect. The first of these laws allowed for the establishment of competitive telecommunications companies. It divided the sector into two categories: firms that own telecommunications facilities themselves (type I), and firms that rent these facilities (type II). The two categories are regulated separately. By 1987 ten type I carriers were operating in the Japanese industry, and by 1988 seventeen type II carriers were providing nationwide services. There were more than four hundred carriers in total. The Ministry of Post and Telecommunications continues to regulate rates according to a rate of return calculation as well as other aspects of service and is pledged to restrain ruinous competition. ${ }^{16}$

The second law privatized NTT, which now provides both type I and

15. Akihiro Yoshikawa. 1985. “Telecommunications Issues in Japan.”' In Borrus and others (1985).

16. Nambu, Suzuki, and Honda (1989, pp. 149-50). 
type II service. It faces competition in its most profitable markets, such as Tokyo-Osaka, but is still obliged to provide universal coverage. This has prevented NTT from optimizing its network and pricing structure. In addition, NTT Data Communications System was broken out of the original NTT Corporation to provide data communications services in competition with other type II providers.

In summary, therefore, the Japanese telecommunications industry was a public monopoly until 1985, although with incremental deregulation starting in 1971. The industry has been privatized since 1985 , and competition to provide local service is greater than in the United States. Rate regulation remains, however, to blunt the effect of the competition.

Telecommunications in France. The French telephone system had a bad reputation for many years. In the 1960s the telephone density in France was only one-sixth that of Sweden, and service was very poor indeed. As recently as the 1970 s, it was said that "half the country was waiting for a phone and the other half for a dial tone." ${ }_{17}$ The network was a government-run monopoly administered through the Ministry of Posts and Telecommunications, which gave low priority to telephone service. De Gaulle regarded the telephone as a gadget. Telephone equipment was purchased on a cost-plus basis without competitive bidding, leading to prices for equipment that were higher than those available from international suppliers. In 1969 it was estimated that it would take nine years to clear 99 percent of all requests for service, compared with three days for the United States, and 25 percent of calls from Paris to other cities in France were not completed. ${ }^{18}$

As a result of the inadequate services political pressure built up for change. Rather than changing the system, however, the French parliament designated telecommunications as a priority in the economic plan that it enacted in 1976 and provided a huge increase in investment resources. To the extent that there was institutional change, it came within the Ministry of Posts and Telecommunications, where the power of the postal administrators was reduced to the benefit of telecommunications.

Even before the changes within the French ministry, institutional

18. Ergas (1992, p. 3). 
decisions had been made that affected profoundly the subsequent development of the French industry. During World War II a national center for telecommunications research and a training center for telecommunications engineers were established. The technical experts who were trained through these centers worked with local equipment supply companies on projects such as the first fully digital switch, developed in 1971. Once the funds for modernization were made available, there was strong technical expertise within the Ministry of Posts and Telecommunications to modernize the network.

By 1989 the French telecommunications network, now called France Telecom, had been completely transformed, and it is now one of the most modern in the world. From an economic, rather than a purely technical, vantage point, however, the French industry has experienced some difficulties.

First, the equipment supply industry has not been able to adapt the technologies that it developed for the French network for sale overseas. Both ITT and Ericsson were pushed out of the French industry, leaving the French companies Alcatel and Thomson as the main suppliers to France Telecom. These companies experienced difficulties, however, and both were nationalized by 1981 . When the government became responsible for making up the losses incurred by Thomson, it decided that this company should leave the telecommunications supply business, leaving Alcatel as a monopoly supplier. Alcatel used the profits from its sales in France to finance a push into the U.S. equipment market but has not succeeded so far. ${ }^{19}$

Within France Telecom, a series of ambitious programs was instituted: the "videotex" program to distribute terminals free to subscribers; an "integrated services digital network" to provide advanced data transmission services; cable television; consumer-oriented facsimile, a plan to provide low-cost fax machines to households; cellular mobile telephone service; and intelligent network services of the kind provided by the Bell operating companies in the United States. None of these programs has become commercially viable, even by France Telecom's standards, despite large-scale investment. Moreover, not only has France Telecom tried to push into areas that have not turned out to be

19. One of the local Bell companies has tried Alcatel's "Minitel"' system in test markets, but the reactions have not been favorable. 
commercially viable, it has also missed opportunities, such as traditional fax service and pagers, that would have been profitable.

In summary, the fact that telecommunications has been and still is a public monopoly has had profound effects on the evolution of the industry. When the government gave telecommunications a low priority, the system was inefficient and out of date. The excess demand for service was huge. When policy changed, service improved rapidly, but problems have emerged both in the equipment supply industry and in France Telecom. The industry has fallen into the "Concorde trap" of creating a technologically advanced industry with commercial weaknesses. Using profits from its monopoly position in both equipment supply and provision of services, the French telecommunications sector has funded a series of expensive and unprofitable technology experiments.

Telecommunications in Germany and the United Kingdom. The telecommunications networks in both of these countries were operated by public monopolies going back to the early years of the century and before. The U.K. system was operated by the Post Office, and equipment has been supplied primarily by three domestic companies: General Electric Company (no relation to the U.S. company), Plessey, and Standard Telephone and Cable. The German system was and still is operated by the Bundespost, ${ }^{20}$ and it too has used a small group of domestic suppliers for most of its equipment purchases, notably Siemens and Nixdorf.

Both networks have suffered from inefficiencies associated with their ownership and lack of competition. They were ahead of the French telephone system in the 1960s and were able to provide a level of service that kept public criticism at bay. But the domestic equipment suppliers have not kept up with international standards of technology. The German system today relies primarily on mechanical switching devices. Germany's well-deserved reputation for precision engineering has given it the best mechanical switches in the world, except that everyone else has already moved or is moving to electronic or digital switching. The Bundespost is now also changing over to the new technology but lags far behind other countries. For example, high-speed data transmission is not available in Germany.

The difficulties in Germany and the United Kingdom with shifting

20. The predecessor to the Bundespost was the German Imperial Post. 
to advanced technology have not been solely the result of management. In both countries strong postal unions have resisted layoffs and changes in work practices that they fear would result from innovation.

There have been movements toward liberalization of the procurement process in Germany, but policy remains committed to a public system, and, with the difficulties in East Germany, potential layoffs from telecom reform are a concern. In the United Kingdom, Prime Minister Margaret Thatcher embraced privatization, and British Telecom (BT) was born in the 1980s. Mrs. Thatcher does not seem to have done as good a job at promoting competition. Working presumably on the principle that contestability was enough, policy has permitted competition without ensuring effective competition. Mercury has entered the market to compete with BT, but network externalities are very strong in this industry, and Mercury has had difficulties. BT almost completely monopolizes local phone service, and Mercury had only 3 percent of the long-distance market in 1990. There is effective competition for cellular service, data transmission, and private networks, and Mrs. Thatcher's policy may end up being vindicated. More effective competition on local and long-distance phone service seems likely to emerge over time-cable TV companies are now developing telephone capability.

In summary, performance in the telecommunications industries in Germany and the United Kingdom at the end of the 1980s was still dominated by the legacy of state ownership and monopoly. The United Kingdom has moved to privatize its industry and make it more competitive, but reports are mixed on whether this has improved service. As of 1990, effective competition was very limited.

\section{Restrictions on Retailing}

In most countries the retail distribution system is highly regulated. ${ }^{21}$ Regulations control entry in some countries; most countries regulate zoning, opening hours, the marketing techniques that can be used, and the interactions between retailers and suppliers. The regulation of retailing is most severe in Japan, and the nature of the restrictions is

21. This section draws on Abe (1991); Betancourt (1992); Dodwell Marketing Consultants (1991); OECD Working Party No. 1 (1992); Oi (1992); Smith and Hitchens (1985). For Japan I have relied heavily on the compilation of materials prepared by Yanagida (1991). 
described in detail below. In European countries the most important limit on competition is rigid zoning law that prevents entry of new retailing formats with efficient scales of operations. The United Kingdom has no national zoning law that prevents entry into the industry, but in practice zoning laws have been used vigorously to restrict new large stores or malls from developing to undermine the existing retail base. Germany has restrictive zoning laws, but perhaps the most important regulation there is that stores may be open only during regular business hours. In France a law restricting the opening of large stores was enacted in 1973 and has slowed the introduction of larger stores and malls, even though the law has been less rigorously enforced in the 1980s.

Regulation has prevented the competitive evolution of the industry and has inhibited the diffusion of innovations or changes in structure in general merchandise retailing. These innovations generally have originated in the United States. For example, checkout operations and inventories have been computerized with the use of optical scanners. Self-service formats are now more prominent, as are larger establishments and the development of so-called "category killers," such as Home Depot, Circuit City, and Toys ' $R$ ' Us, which specialize in discounting large volumes in particular segments of the market.

The Wal-Mart Phenomenon. Wal-Mart illustrates the process of structural change that has taken place in the United States. It has competed in the South and Southwest by locating at sites within driving distance of several small communities. Wal-Mart then uses lower prices to undercut the small local stores and eventually drives them out of business. One reason it is able to do this reflects another important structural change taking place in the retailing industry: integration of the distribution system has eliminated wholesaling as a separate activity. As one observer summarized, "Stand-alone stores are, in effect, being replaced by 'vertical marketing systems' - that is: 'professionally managed and centrally programmed networks . . . designed to achieve technological, managerial and promotional economies through the integration, co-ordination and synchronisation of the marketing flows from points of production to points of ultimate use. , , 22

These trends have met some resistance as the competition from the

22. Quoted in OECD Working Party No. 1 (1992, p. 19). 
large entrants drives existing retailers out of business. In the United States, however, this resistance has not prevented the growth of largescale and franchised outlets, but in Europe and Japan the political influence of small retailers has been sufficient to inhibit the growth of higher productivity retailing formats.

Retailing in Europe and Japan has also been affected by decisions about the transportation system. The large-scale or specialized high productivity retailing formats require large customer volumes to compete effectively. In the United States the automobile allows such stores to draw customers from a wide catchment area. In Europe and Japan access by auto, bus, or train is controlled in ways that favor the existing retail base rather than providing access to new competitors.

Specific Restrictions in Japan. In Japan the flow of goods from manufacturers to consumers is channeled through large numbers of small-scale distributors, both at the wholesale and retail level. ${ }^{23}$ These small-scale firms have little bargaining power against the large manufacturers that supply them with their products. Manufacturers routinely set retail prices, as do import distributors, and penalize those distributors that violate the price guidelines. Distributors often have the privilege of returning unsold merchandise, a provision that discourages the discounting of unsold inventory. In some cases "complicated and ingenious measures" are used to keep imported goods that compete directly with brand-name domestic products out of the distribution system. ${ }^{24}$

Some specific ways in which manufacturers maintain resale prices include: (a) clauses in the supply contract that require a given price, (b) requirements that distributors pledge in writing to use specific prices, (c) requirements that distributors report on the prices they charge for products, and (d) indications that manufacturers will stop doing business with distributors that violate preset prices. Manufacturers also penalize distributors who violate price agreements by forbidding them to advertise lower prices and by withholding rebates.

23. The nature of the Japanese distribution system is described in a 1990 report from an advisory group to the Japan Fair Trade Commission. The report was entitled "Distribution System, Business Practices, and Perspective of Competition Policy-For Promotion and the Protection of Consumer's Interests." The provisional translation of this report was issued on June 21, 1990. See Yanagida (1991, p. 6.08).

24. Yanagida (1991, p. 6.10). 
The importance attached to resale price maintenance is shown by an article in The Daily Yomiuri of July $24,1990 .{ }^{25}$ The newspaper reported that Matsushita was still feuding with the Daiei supermarket chain after twenty-six years. Matsushita refused to supply the chain in 1964 because it violated the resale price maintenance provisions. After the founder of Matsushita died in 1989, Daiei tried to reestablish relations with the company but was still unsuccessful as of the date of the article.

Manufacturers in Japan use other methods besides retail price maintenance to reduce competition. They have tied-brand stores that sell only the products of a particular manufacturer, and they assign geographic areas to these stores to discourage competition among them. For example, The Japan Economic Journal of June 3, 1990, reported that of 63,000 exclusive stores selling home appliances, 24,000 carried Matsushita products only, and 11,000, Toshiba products. ${ }^{26}$ These stores receive an average retail margin of 25 percent, higher than that for independents; in addition, they receive higher rebates than independent stores. The power of these stores is declining, however. In 1990 they had 40 percent of the market, down from 60 percent a decade earlier.

Perhaps the most important regulation affecting productivity in retailing is the notorious 'Large-Scale Retail Stores Law.', The working of this law was described by Kazuo Sato, the secretary general of the Medium and Small Enterprises International Center in 1989. ${ }^{27}$

Before World War II a "Department Stores Law" was enacted to protect small- and medium-size retailers. This law was abolished after the war, but in 1956 a similar statute with the same name was adopted. Under this law retailers that had more than a specific number of square meters of selling space, depending on the city where the facility was located, were regarded as department stores and had to obtain a license to open. Processing and repair facilities were counted as retailers under this law.

In the early 1970s the government came under pressure both from supermarkets wanting to open large facilities and from small retailers complaining about shopping malls. Consequently, the "Large-Scale

25. See Yanagida (1991, p. 6.18).

26. See Yanagida (1991, p. 6.17).

27. Kazuo Sato, "Distribution System in Japan: Large-Scale Store Law and the Application,' Japan Business Law Letter, December 1989, pp. 1-8. See Yanagida (1991, pp. 6.40-6.47). 
Store Law" was enacted in 1973. One of its stated purposes was to protect consumers' interests and facilitate more openings of large stores. Whereas the Department Stores Law required a store to have a license before it opened, the new law required only that the proposed new store report its intention. In practice, however, the difference between the two laws was not as great as it seemed. The new law stated that it would operate by "adjusting the business of large retailers as well as securing business opportunities for the neighboring small- and medium-scale retailers.' 'Existing small retailers could object to a new store before it was built. And after reviewing the plans of the new store and the objections of the existing retailers, authorities could reduce the floor space or delay the opening if they determined that neighboring small- and medium-size stores would be adversely affected. In addition, the law stated that malls (defined as a collection of small, independent stores operating in one large facility) would be subject to control under the terms of the law as if they were large-scale stores. In 1978 the law was amended to cover new stores that had only 500 square meters of selling space.

In principle, the procedure for gaining permission to open a large store was to be handled expeditiously. But in practice many large stores have opened seven to ten years after the planned facility was announced. ${ }^{28}$ The Ministry of International Trade and Industry (MITI) issued "administrative guidance', in 1979 to speed applications, but this was not very successful. Moreover, the power of MITI to affect store openings is limited because in many cases local government regulations are superimposed on the national law. Some localities restrict openings of stores of more than 200 to 300 square meters, and some restrict virtually all stores whose capital is provided by nonresidents of the city.

Partly in response to pressure from the United States, national policymakers in Japan have taken some steps to relax the existing laws, and MITI issued a report, "Distribution System in the 1990s,' that set out measures intended to achieve a more open and competitive system. The closing time has been extended one hour, to 7 P.M., and the number of closing days has been lowered to forty-five a year, from forty-eight.

28. It is said that large bribes and lawyers' fees often have to be paid to secure permission and that many prospective new store owners give up the struggle. 
And MITI promised to ask local governments to reduce their regulatory burden. The proposals in this document do not amend the fundamental provisions of the Large-Scale Store Law, however, so it is not clear how effective the reforms will be, particularly given local controls. As of April 6, 1990, The Daily Yomiuri reported that more than 1,190 applications to open large stores were awaiting approval. ${ }^{29}$

\section{Conclusions on Specific Regulations}

This compilation of restrictions in Europe and Japan makes an a priori case that the complex and ubiquitous regulatory structure there lessens effective competition. In cases of monopoly or oligopoly (telecommunications, banks, and airlines), the nature of the regulation or the extent of state ownership discourages active competition. In the case of retailing, small shopkeepers are protected against new retailing formats.

Two of the industries, banking and telecommunications, are still subject to restrictive regulation in the United States. The restrictions on interstate banking have led to a nonoptimal industry structure with too many small banks. The benefits of competition have offset this disadvantage, however. In the case of telecommunications, the United States has had the benefit of private ownership. And rates have been regulated in such a way that productivity increases accrued to the Bell system between rate changes. Table 2 summarizes the key points in the economic environments in these four industries for the United States and the other countries.

Among the foreign industries, retailing in Japan stands out as an industry that has been subject to very restrictive regulation. European airlines (with the exception of British Airways) and banks and telecommunications in Germany and the United Kingdom are also strictly regulated industries that have paid a substantial productivity price.

One obvious exception tests the rule that regulation reduces productivity-retailing in Germany. The regulatory environment in Germany is quite restrictive, notably in the setting of opening hours, but productivity (as measured) is high. I will discuss why this might be when I review that case study.

I turn now to a discussion of productivity comparisons in these in-

29. See Yanagida (1991, p. 6.48). 


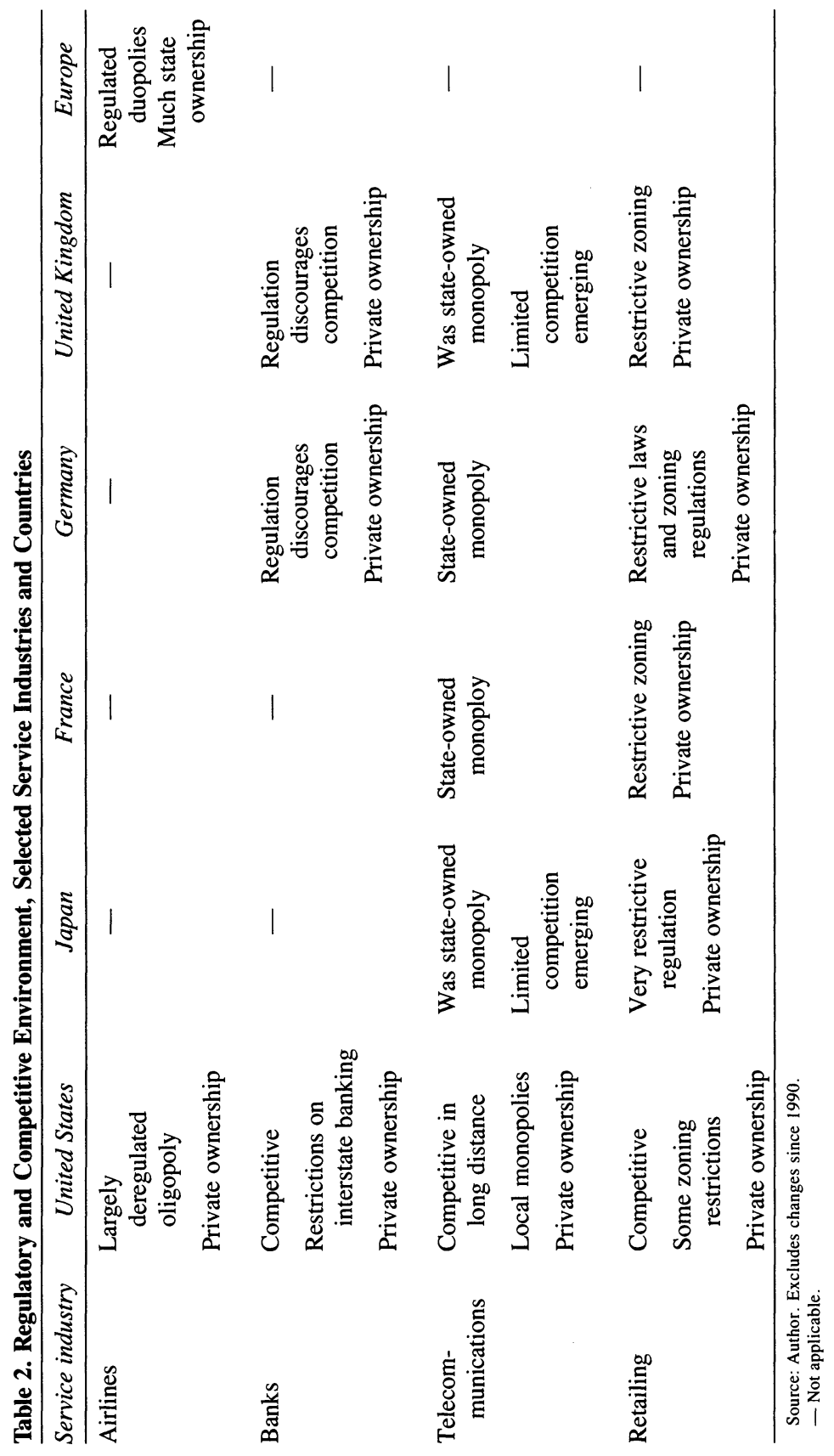


dustries. The comparisons were made by a research team, of which I was a member, sponsored by the McKinsey Global Institute. ${ }^{30}$

\section{U.S. and European Airlines}

We made a comparison of output per employee in the passenger airline industries of Western Europe and the United States for 1989. ${ }^{31}$ The study covered 171 carriers in the United States, including 11 major carriers and 160 regional and commuter carriers. For Europe there were 89 carriers, including 12 major or national flag carriers, 28 regional or commuter carriers, and 49 charter carriers. Cargo carriers were excluded from the analysis. The U.S. carriers employed 476,000 people in 1989 and carried 493 million passengers a total of 702 billion passenger kilometers. The European industry employed 377,000 people and carried 250 million passengers a total of 436 billion kilometers. Figure 2 shows the structure of the two industries, illustrating that the major scheduled air carriers have a greater share of the U.S. market than they do of the European market. ${ }^{32}$

\section{Measuring Productivity}

In constructing a measure for overall productivity for the airline industries, we used the approach known as "functional productivity." In this approach each airline is assumed to be composed of a set of separate functional activities, consisting of the following:

30. The comparisons of productivity are based on McKinsey Global Institute (1992). The study was directed by William Lewis of the McKinsey Global Institute. Andreas Siemen, Mike Balay, and Koji Sakate of the Global Institute and Heidi Wiedenman of the University of Maryland worked on the study. Francis Bator of Harvard University, Robert Solow of the Massachusetts Institute of Technology, Ted Hall of McKinsey, and I were members of an advisory panel and wrote parts of the final report. Thierry Noyelle and Thomas Stanback of Columbia University and many McKinsey staff members provided additional assistance.

31. Because I will be making use of the results of a research team of which I was only one member, I will refer to results that "we" found.

32. A scheduled passenger service is a regularly scheduled route that is flown according to a published schedule. Charter flights are provided on an irregular basis and are generally associated with low-cost leisure travel. 
- The flying of the planes: output measured by hours flown, labor input by cockpit personnel.

- The service provided within the cabin: output measured by passenger kilometers, labor input by cabin personnel.

- Airport handling: output measured by number of passengers transported, labor input including personnel for ramp and passenger handling, cargo, catering, cleaning, security, ground equipment maintenance, cabin crew management, and training.

- Aircraft engineering and maintenance: output measured by standardized fleet maintained, labor input by engineering and maintenance personnel, including administration.

- Ticketing: output measured by passengers transported, labor input by personnel involved in reservations and ticketing, marketing, scheduling, and tariff setting.

- Other activities: output measured by passengers transported, labor input by general management, corporate administration, and planning personnel.

Using this approach, we then calculated a separate estimate of output per employee for each of the activities. These estimates cannot be compared across activities because the units of output measurement are different, but for each one a comparison can be made for the United States and Europe. Thus, we found, for example, that the productivity of the maintenance activity in Europe was only about 57 percent of the U.S. level; the productivity of the passenger handling activity in Europe was 89 percent of the U.S. level.

In making these comparisons we investigated some adjustments that might be important because of the differences in industry structures. The European industry carries more cargo in its passenger aircraft than does the U.S. industry, where cargo travels on specialized cargo carriers such as Federal Express. We adjusted for this by estimating the number of personnel involved in cargo handling and excluding these from the totals. Our estimate was based on the average ratio of tons transported per cargo service employee, which we obtained for selected U.S. and European airlines.

We also considered the role of travel agents in providing ticketing services but were not able to make an adjustment for this. Although we 
Figure 3. Productivity Levels of the European Airline Industry, 1989

$$
\text { U.S. Productivity }=100
$$

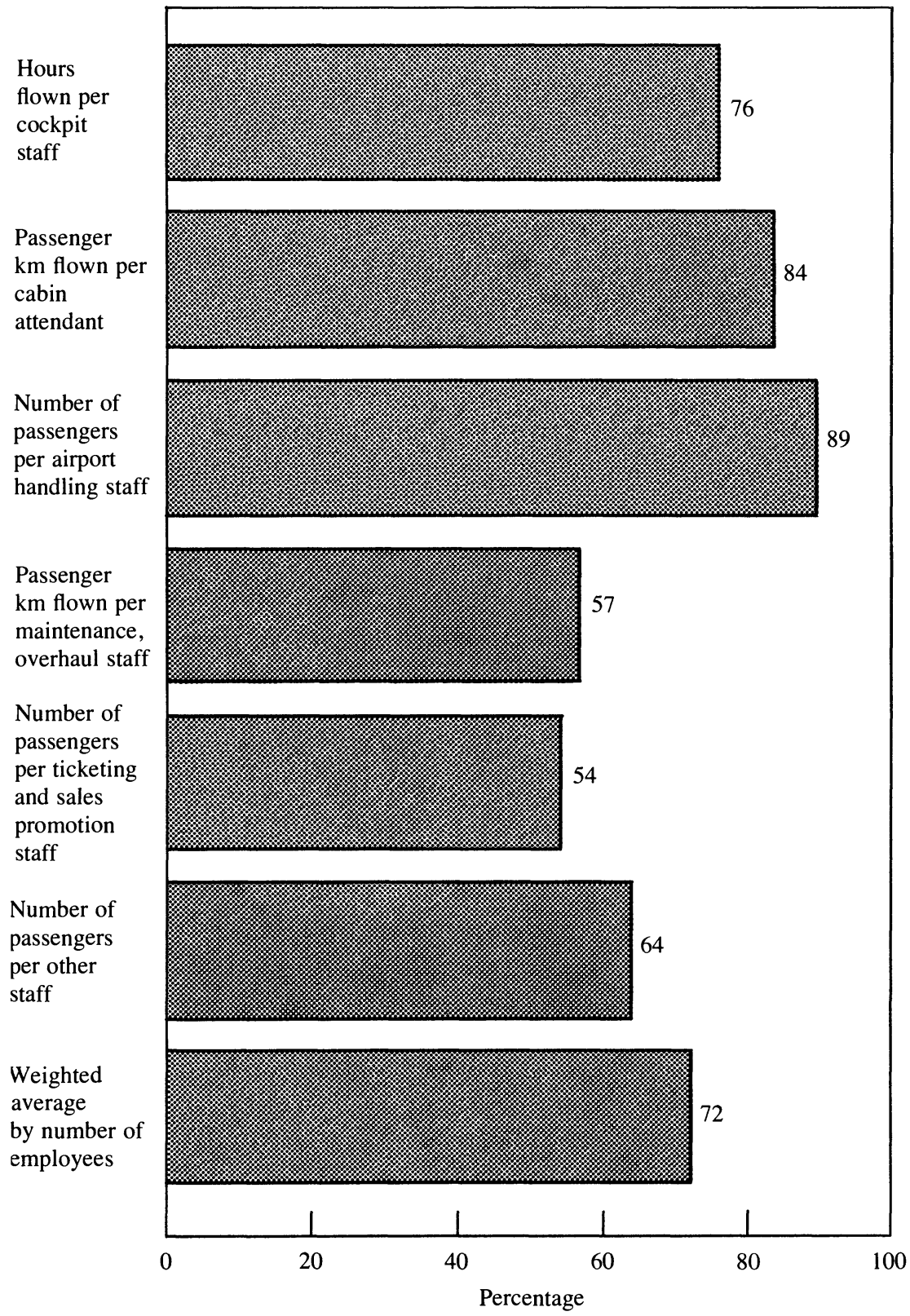


lacked quantitative data, industry participants told us that reliance on travel agents for ticketing is about the same in the two markets.

Airlines provide maintenance for other airlines or contract out their own work. And airports, particularly European airports, or their agents provide baggage handling or other ground services for airlines. The contracting out of maintenance work cancels out and does not bias the industry level results. We attempted to adjust for contract work to airlines outside the respective markets and for services provided by airports or outside contractors. We made a rough estimate that about 5,000 personnel provided maintenance services to U.S. airlines that were not counted in our data, and these were added to the U.S. total. Unfortunately, we were not able to find reliable figures to make the adjustment to European airlines for outside ground personnel. We did conclude, however, that this adjustment would certainly work to reduce the relative productivity of the European airlines.

The maintenance required by a given fleet depends on the characteristics of the fleet, particularly the age of the planes. We did not make a specific adjustment for age, but the U.S. fleet is older than the European fleet, giving the U.S. a small disadvantage.

After making these adjustments or assessing the effects of differences for which we could not make adjustments, we then combined the activity productivities into an estimate of the weighted average productivity of the European airlines compared with those of the United States The weights used were the shares of employment in each activity. Figure 3 shows that U.S. productivity was higher in all of the individual activities of the industry, with notably low productivities in Europe occurring in maintenance, ticketing, and other personnel. Overall, productivity for the European airlines was estimated at 72 percent of U.S. productivity. These data ignore quality differences, but the importance of such differences is assessed below.

Business analysts often look at separate activities and productivities to find areas of weak performance within individual companies. It is not the approach of choice for productivity economists, who prefer a Divisia output index. That is not possible here because revenue shares are not broken out for the separate activities. Our approach is similar to the one used by the Bureau of Labor Statistics (BLS) in its estimates of productivity in selected industries. In practice the method of calculation is very unlikely to be crucial. Figure 3 shows consistently lower 
relative productivity in the European airlines in all of the activities, so index number difficulties are unlikely to account for the overall result. In addition, we have erred against the U.S. airlines where there was doubt about the numbers. ${ }^{33} \mathrm{We}$ concluded, therefore, that the productivity gap between the European airlines and the U.S. airlines is substantial. ${ }^{34}$

\section{Reasons for the Productivity Difference at the Production Level}

The first possible explanation for the productivity gap is the hub and spoke system that the U.S. industry has developed since it was deregulated. This system allows an airline to feed its aircraft from multiple feeder flights into a hub airport at about the same time. The passengers then change planes, although staying with the same airline, and the fleet takes off again. This system offers, substantial advantages to passengers because it allows much greater frequency of flights. For example, American Airlines can feed passengers from all over the Southwest into Dallas-Ft. Worth and then send them out to cities in the rest of the country. This happens every two or three hours, allowing a passenger who wants to travel from, say, Tucson, Arizona, to Charlotte, North Carolina, the opportunity to select from several flights a day. The volume of traffic between these two cities would not otherwise allow such frequent service.

Passengers sometimes complain about the hub and spoke system because it means that they have to change planes at the hub. This is costly, although less costly than changing terminals and airlines. Our information from the airlines is that the hub and spoke system emerged because of competitive pressure to provide frequent service, that is, it is consumer-driven. Passengers probably fail to realize that there would be many fewer flights without hub and spoke and that there would be much longer waits between flights when changes were required. This assessment agrees with that of Robert Gordon, who states that the

33. It is also the case that British Airways, the largest European carrier, now has productivity similar to that of the U.S. carriers. Without British Airways, the European average would be lower. British Airways competes directly with U.S. carriers on transatlantic routes.

34. Our results are consistent with Caves and others (1987), who found that after U.S. deregulation, U.S. airlines achieved more rapid growth than European airlines did. 
establishment of new hubs has increased the number of nonstop routings and that few nonstop routes have been discontinued. ${ }^{35}$

An earlier study of airline productivity had argued that the hub and spoke system provided a productivity advantage to the U.S. airlines. ${ }^{36}$ If customer convenience were properly accounted for in the output measure, then this would be the case. Given the measures of output that we use here, however, we concluded that the hub and spoke system actually gives a productivity disadvantage to the U.S. airlines. ${ }^{37}$ This possibility first emerged in discussions with industry participants, who pointed out that the system creates severe congestion problems for them. The charts shown in figure 4 support the idea. Northwest operates a hub out of Minneapolis-St. Paul and has its arrivals and departures set up in a series of eight "banks." The result is that large numbers of arrivals, grouped at two- to three-hour intervals, are followed by large numbers of departures - as many as thirty-two in a half-hour period.

Many of us have experienced terminals that were packed with people for a period and then nearly empty for a while after that. At the DallasFt. Worth hub, for example, American's planes line up in a long row waiting to take off. Half an hour later very few flights are preparing to leave.

Airports that do not operate hub and spoke have less of a peak load problem. Figure 4 also shows flights into Heathrow airport, where there is clearly less peaking. British Airways operates with five to ten arrivals in each half hour. Even the total number of flights into the airport in any half-hour period rarely reaches the peak that Northwest alone has in some periods. ${ }^{38}$

Another possible reason for the productivity gap is that U.S. airlines may have higher rates of capacity utilization than do the European

35. Gordon (1992).

36. Noyelle and Stanback (1992).

37. At the risk of repetition and in response to several readers' comments, I stress that this is a productivity disadvantage only because we have an output measure that fails to capture the value to consumers of the service frequency that is increased by hub and spoke. There is no mystery about why the airlines adopt hub and spoke-consumers vote for it by their purchasing decisions. I note a New York Times report that points to the costs of operating hub and spoke. Some airlines are abandoning such operations where the volume of traffic does not justify it. See Agis Salpukos, "Hurt in Expansion, Airlines Cut Back and May Sell Hubs," New York Times, April 1, 1993, A1.

38. We also checked the pattern of arrivals and departures in other airports to confirm the examples given in figure 4 . 


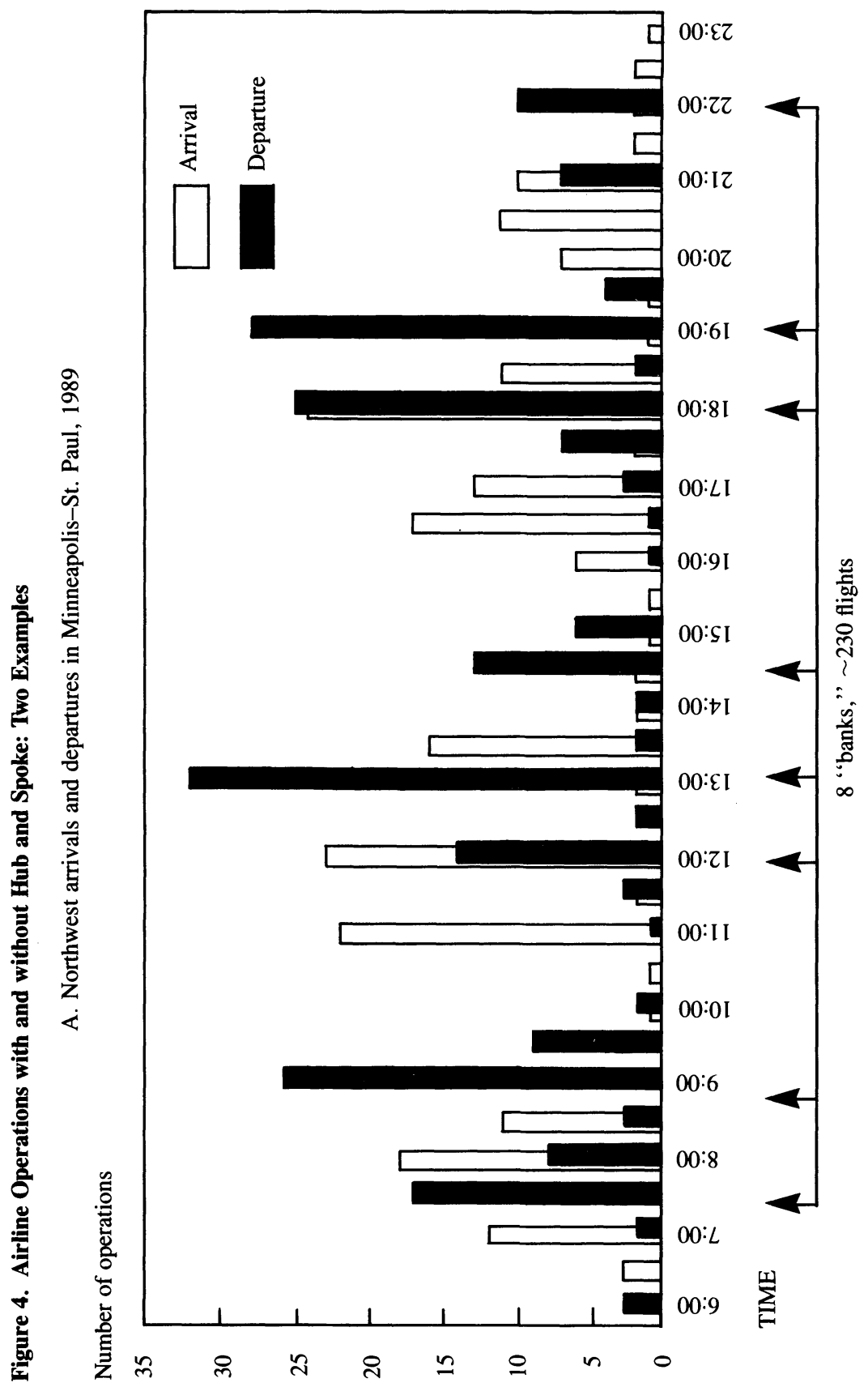




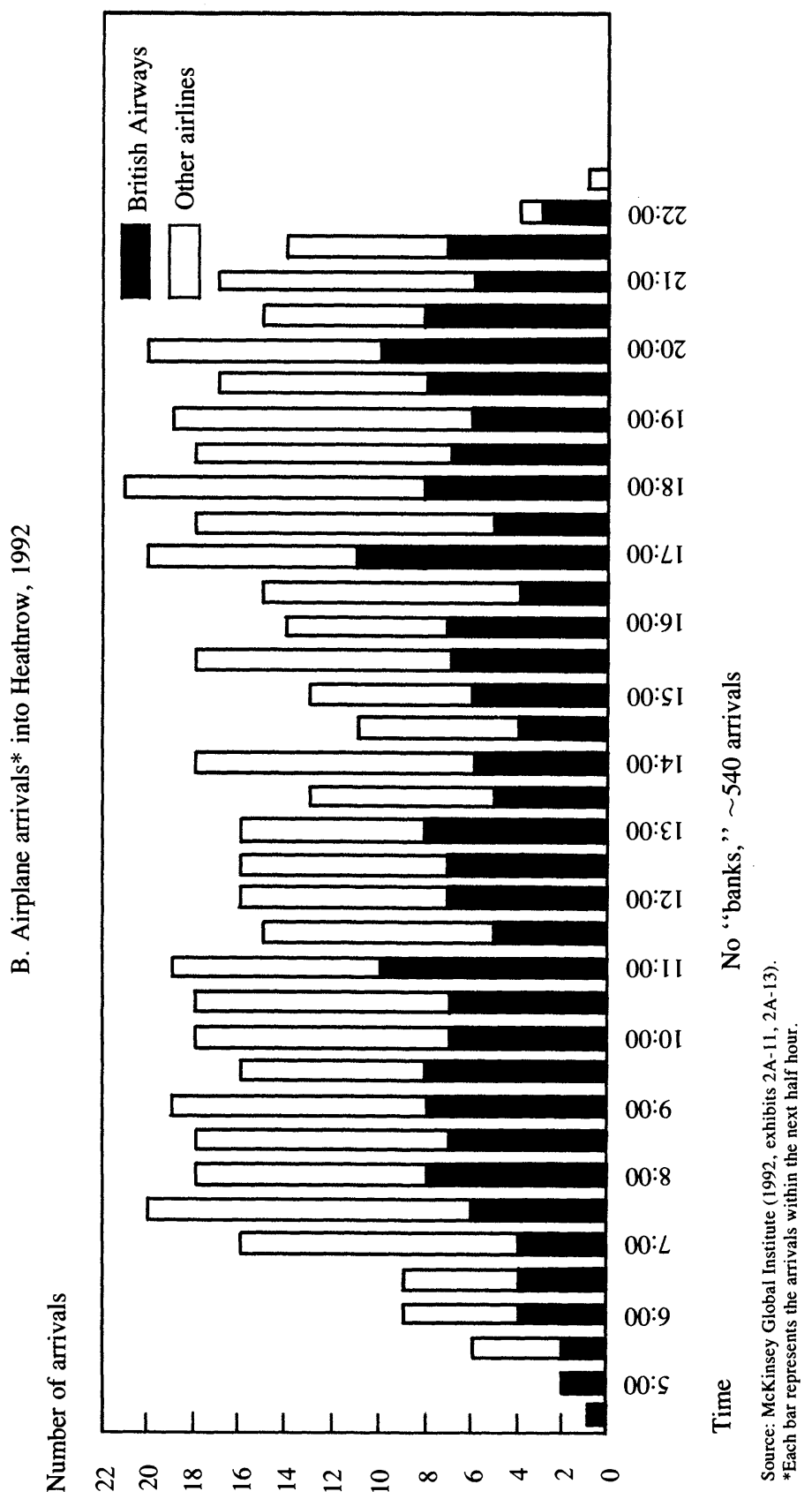


Figure 5. Functional Productivities For U.S. and European Airline Personnel, 1989

A. Cockpit crew productivity

\section{U.S. average $=100$}

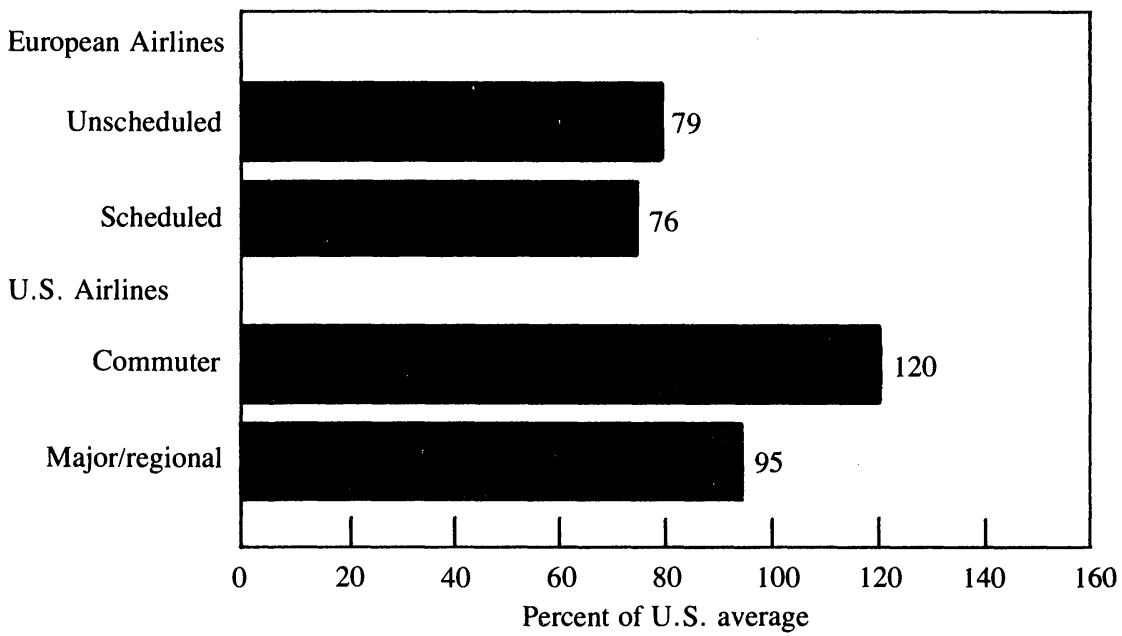

B. Cabin attendant productivity

\section{U.S. average $=100$}

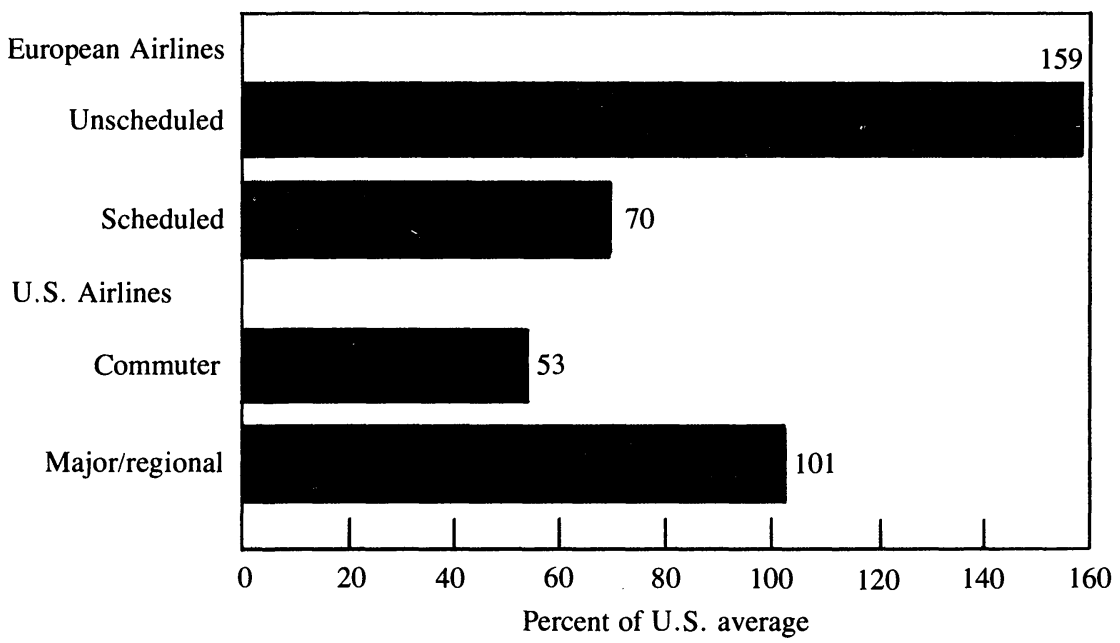


airlines. We found that not to be the case. On average U.S. planes were flown for 7.2 hours a day in 1989, while the average for the European airlines was 6.9 hours. It does not appear that utilization is a major reason for the productivity gap.

We found that the productivity of the cockpit and cabin crews varies, depending on whether the flight is scheduled or unscheduled, whether it is a long (intercontinental) flight or a short one, and the type of aircraft flown (see figure 5). Based on these differences, we estimated that the observed differences in the productivity of the cockpit crew resulted from structural differences in the industries. In particular, intercontinental flights require longer layover periods for flight crews, and the European airlines have more of these flights.

We were not able to obtain direct estimates of capital-labor ratios for the two industries, but we found little evidence that capital is a major explanatory factor for the productivity differences. All of the airlines use aircraft from the same three suppliers. And although the fleets differ in structure, the average cockpit crew size is about the same, with three-person crews in 26.3 percent of the planes in the United States, compared with 26.5 percent in Europe. ${ }^{39}$ All of the airlines have computerized their operations for handling reservations and ticketing and for managing aircraft and personnel. The computer systems were developed in the United States but are available worldwide. The U.S. industry has invested more heavily in information technology, but this results from operating frequent flier programs and other marketing strategies.

There are some indications that economies of scale were a cause of higher productivity of the United States industry.

- Ninety-one major airports in the United States served 900 million passengers in 1989, or an average of 9.9 million per airport. This compares with 56 major airports in Europe serving 416 million passengers, or 7.4 million per airport. ${ }^{40}$

- The eleven largest U.S. airlines in 1989 had an average of 290 planes, compared with an average fleet of 95 planes for the nine largest European carriers.

40. McKinsey Global Institute (1992, exhibits 2A-20, 2A-21). 
These size differences translate into productivity differences in airport handling, where capital and labor can be used more efficiently at larger scale, and also in fleet maintenance. To be considered efficient, a maintenance operation needs between fifteen and twenty-five planes of the same type, and many European airlines fall below this critical level.

The effects of scale should not be exaggerated, however. The lack of scale in ground handling in European airports has led to a pooling of airport handling facilities through the use of outside contractors. There does not appear to be a significant scale penalty in practice; in fact, some observers of the industry argue that very large airports are less efficient. ${ }^{41}$ And the small fleet sizes have led European airlines to offer fleet maintenance services to non-European airlines so that they can operate with efficient scale. A penalty is likely to be associated with maintaining the planes of other airlines, however, in terms of scheduling the maintenance so that it is done efficiently. In any case, the scale penalty faced by the European airlines is itself a result of the industry structure and the regulatory climate rather than of too small a market.

We assessed service quality level without being able to provide good quantitative evidence. On one hand, many people would argue that Swissair or other European airlines provide a higher level of service and better meals than do U.S. airlines. On the other hand, the charter flights in Europe, a large fraction of total flights, operate with a minimum of cabin staff and service. And the frequency of flights provided by the U.S. hub and spoke system is greater than that in Europe.

In summary, we found that the techniques of production used in the two airline industries were similar indeed. Capital and technology do not seem to be major sources of the productivity difference. The differences in route structures account for the differences in cockpit personnel productivity, and scale differences may account for some of the maintenance productivity difference. But overall, the causal factors that we have described do not seem adequate to explain fully the differences in productivity between the two industries. Partly as a residual explanation, therefore, we argue that the European airlines are less efficient

41. Art Buchwald claims he was told, when he missed his flight from O'Hare to Wisconsin, that he could easily finish his trip on foot because he already had walked most of the way just getting to the gate. 
at operating their systems and have excess labor in maintenance, ticketing, and other operations. Although it has not been possible to document this hypothesis from written material, there is strong anecdotal evidence from industry participants to support it. Managers in European airlines admit that they are overstaffed in many areas and state that they are unable to change their staffing levels because of union rules and political opposition to layoffs.

Since 1990 competition has increased in Europe, and the smaller airlines are consolidating. Alliances are also forming between U.S. and European airlines. Provided Europe opens its markets to full competition, there is no reason that full convergence of productivity could not happen quickly. At the same time, the European airlines are still finding themselves at a disadvantage in direct competition with U.S. airlines. Richard Weintraub reports that the share of passengers carried by U.S. airlines to and from Germany and France is rising rapidly and that the shares for French and German airlines are falling rapidly. ${ }^{42}$

\section{U.S., German, and U. K. Banks}

In 1989 the United States had 2.29 million workers in depository institutions, Germany had 703,000, and the United Kingdom 522,000. Our study concentrated on retail banking, and so excluded employees of other sorts of depository institutions from the total to obtain the employment figures for this sector. Some employees of the Federal Reserve and the Bundesbank were included in our employment totals to make them comparable to the U.K. figures, where the payments system is operated by the commercial banks.

\section{Productivity Measures}

Our output measure for the banks was based on the procedure the BLS uses. The three main components of output are number of transactions, number of accounts, and number of credits outstanding. The detailed elements in these three are as follows:

42. Richard M. Weintraub, “Flying High Over Europe,' Washington Post, August 1, 1993, H1, H4. His data are from the Immigration and Naturalization Service and American Airlines. 
- Transactions: checks and NOWs (negotiable orders of withdrawal) cleared; paper credit transfers; standing orders; direct debits; electronic funds transfers; bills cleared; credit card transactions; counter cash withdrawals.

- Savings and deposit services: regular savings accounts; contractual savings accounts; savings bonds, certificates of deposit, and other savings accounts; time deposits; money market accounts; building society contracts.

- Credit services: revolving credit accounts; installment credits; credit card credits; mortgages; building society contracts.

Based on data provided by the Bank for International Settlements, we estimated the number of payment transactions made per year, counting checks, electronic transfers, and credit card transactions on an equal basis. In this measure of output, we were not able to exclude transactions by large entities (wholesale transactions) except for a few cases (such as Fedwire transactions) where they could be easily identified. ${ }^{43}$ Deposit and credit services are measured by the number of savings or credit accounts operated by the banks. The number of credit accounts was based on data from the American Banking Association, the British Bankers Association, and a 1988 McKinsey analysis of Germany. Using number of accounts means that differences in the sizes of the accounts are ignored.

These data reveal the very high banking "transaction intensity" of the U.S. economy. U.S. banks processed 57.8 billion transactions in 1989 , nearly 300 per person above age 14 . These figures compare with 7.2 billion for the United Kingdom and 8.3 billion for Germany, only slightly more than half the U.S. rate per person. For the number of savings or deposit accounts, the picture is different, with Germany having 184 percent and the United Kingdom 75 percent of the U.S. level of accounts per person. The United States had more credit accounts outstanding, 1.4 per person, compared with 0.9 in the United Kingdom and 0.7 in Germany.

We used an approach similar to that for the airline industry to allocate total banking industry employment to the three bank functions, and then estimated separate functional productivities. The three functional pro-

43. Cash withdrawals using ATMs (automated teller machines) were not included. I discuss ATMs separately below. 
Figure 6. Productivity in Retail Banking for Germany, the United Kingdom, and the United States, 1989
A. Overall productivity ${ }^{a}$
B. Payment transactions and cash with-
U.S. $=100$ drawals at teller per full-time employee
U.S. $=100$
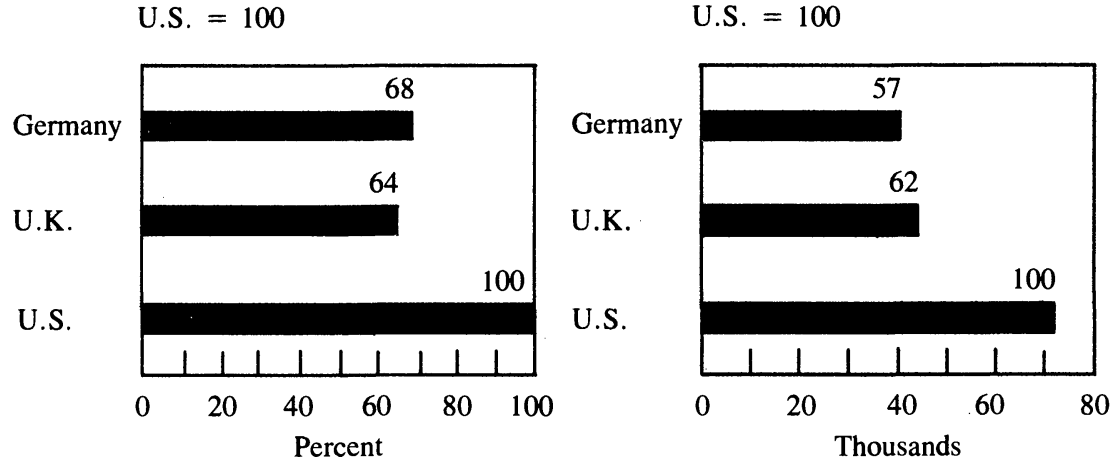

C. Number of deposit accounts per full-time employee

D. Number of credit accounts per full-time employee

$$
\text { U.S. }=100
$$

$$
\text { U.S. }=100
$$
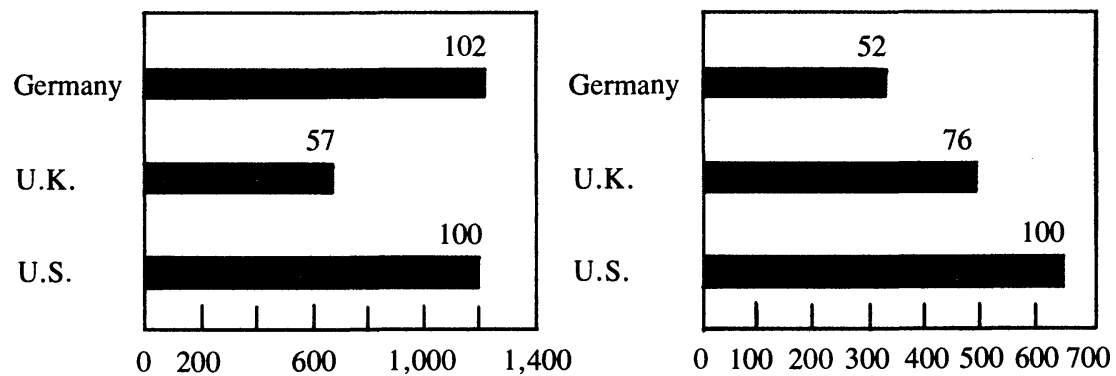

Source: McKinsey Global Institute (1992, exhibits 2B-9, 2B-10).

a. Composite index of productivities for payment, deposit, and credit services weighted by labor input.

ductivities were then averaged to give the overall banking productivities. Figure 6 shows the results. With one exception, the functional productivities in Germany and the United Kingdom were a half to threequarters of the U.S. level. The overall productivity levels were 68 percent for Germany and 64 percent for the United Kingdom, reflecting the fact that transactions processing takes up the largest share of employment in all three countries. It is likely that any reasonable alter- 
native aggregation procedure would show a similar overall productivity gap.

The only exception to this general pattern was the German industry's relatively high productivity in savings accounts. German customers are very thrifty, often open multiple savings accounts, and leave the funds untouched for long periods. Given the nature of our output measure (number of accounts), it is not surprising to see high estimated productivity in Germany in this activity.

\section{Reasons for the Productivity Difference}

As with the airline industries, several possible sources of productivity difference at the production level need to be checked. The first of these is that the mix of services provided in each of the three countries is different.

The payments systems in both Germany and the United Kingdom rely far more heavily on electronic funds transfers than does the U.S. system. Fifty-two percent of German transactions and 21 percent of U.K. transactions are made through electronic transfers; the comparable figure in the United States is 5 percent. This difference should work to the advantage of the United Kingdom and Germany, and, indeed, banking industry experts that we consulted hypothesized that Europe's banking system would show higher productivity than that in the United States.

The differences in mix were less important for deposit accounts. For credit accounts, the U.S. banks were again at a disadvantage because they carry a higher proportion of monthly installment accounts than German and U.K. banks do.

To assess the impact of these mix differences, we estimated the relative labor inputs to process the various kinds of transactions and accounts. This recalculation led to a widening of the productivity gap, with German relative productivity falling to 50 percent of the U.S. level and the United Kingdom to 54 percent.

We assessed differences in service quality in those areas where we could obtain data. Interest rate spreads between savings accounts and loans were higher in Germany and the United Kingdom than in the United States. Opening hours were comparable in the three countries. Access to branches was somewhat less in the United Kingdom and 
somewhat higher in Germany than in the United States. Germany has made it an important goal to provide a cooperative or state-run bank in all small communities. The U.S. industry was ahead in providing access to ATMs (automated teller machines) and machines with more service options. Tourists from Europe complain about long waiting times in U.S. banks, but this appears to result from long lines for processing travelers' checks in tourist cities such as New York. Studies find average waiting times in branches to be similar in all three countries, with the U.S. banks more likely to pool lines to reduce variance among customers in the time waited.

Economies of scale and scope operate at both the firm and establishment levels. ${ }^{44}$ Because of restrictions on interstate banking, the United States has very large numbers of banks and hence a potential disadvantage relative to the United Kingdom due to operations below minimum efficient scale. Germany has large commercial banks and many small savings banks and credit cooperatives. Both the credit unions in the United States and the credit cooperatives in Germany have small branches, averaging seven employees per branch in both countries. But this segment of the industry makes up only 8 percent of total employment in the United States, compared with 24 percent in Germany. Industrywide, the United Kingdom had an average of 19.3 employees per branch; the United States, 15.2 employees; and Germany, 10.7 employees. ${ }^{45}$ According to the McKinsey study, the teller utilization rate in the United States rises from about 40 percent in branches with only three tellers to 80 percent in branches with eight tellers. ${ }^{46}$ Based on the differences in average branch size, we estimated that about five percentage points of the U.S.-German productivity gap of thirty-two points resulted from smaller branch sizes. Adjusting for branch size would widen the U.S.-U.K. gap.

Based upon investment in information technology, there appears to be a capital-technology gap between the United States and Germany and the United Kingdom. Two important and related technological developments have changed retail banking during the 1980s: ATMs, and

44. See Ernst Baltensperger (1972); and Jeffrey A. Clark (1988). I have benefited from discussions with Robert E. Litan on this point.

45. These data exclude postal banks in Germany and the United Kingdom.

46. McKinsey Global Institute (1992, exhibit 2B-19). 
on-line applications in bank branches. ${ }^{47}$ In 1989 far fewer transactions per person passed through ATMs in Germany and the United Kingdom than in the United States. ${ }^{48}$ Some part of the lower productivity of United Kingdom and German banks comes from the labor used to dispense cash to their customers.

Based on 1989 data for the United States, 1990 data for Germany, and 1991 data for the United Kingdom, U.S. banks made much greater use of terminals-seventy-four terminals per 100 employees in the United States, twenty-three in Germany, and seventeen in the United Kingdom. We cannot provide quantitative estimates of the effect these terminals have on productivity, but we think that they are substantial. Many activities that are carried out at a central location in a U.S. bank or contracted out are still conducted at the branch level in Europe. A U.S. teller can use a terminal to access all of a customer's records even when the records are not in the bank. The hardware to computerize bank operations can be obtained on world markets at the same cost to U.S. and European banks, so the capital and technology gap appears to result from management choices in the countries.

The computer gap is a symptom of a more fundamental difference between the U.S. and European industries. Intense competition that developed over the past twenty years has driven the U.S. banks to lower costs. So, too, have their own poor lending policies, which led many of them to the edge of bankruptcy or beyond. They have been continuously streamlining their operations, applying new technologies, and consolidating to achieve scale economies. The European industry has not moved aggressively to lower employment in relation to the volume of transactions and accounts handled.

In summary, the productivity gap between U.S. and European banks results largely from a failure in Germany and the United Kingdom to use information technology effectively within the banks and to streamline their back-office operations. The German banking industry has been

47. Bresnahan (1986) estimates the impact of information technology on productivity and consumer surplus in the banking industry.

48. We separated electronic fund transfers from ATM transactions. Germany provided 665 ATMs per 100,000 inhabitants, compared with 1,852 per 100,000 in the United States. There were 44,300 transactions per ATM in Germany, compared with 52,900 in the United States. The figures for the United Kingdom lie between these two values. We excluded cash dispensed from ATMs in our estimate of the volume of transactions, so we are understating U.S. output of transactions processed. 
able to take advantage of electronic funds transfers, more so than in the United States. Without this, the productivity gap would be larger. Compared with the U.K. banks, the German and U.S. banks suffer from scale disadvantages, especially the German banks with their very small branches.

\section{Telecommunications in France, Germany, Japan, the United Kingdom, and the United States}

Because of the monopoly and regulated structure of telecommunications in several of the countries, the estimation of productivities was easier in this industry in some ways.

In 1989 the U.S. telecommunications industry employed 798,000 people, excluding equipment manufacture and call completion services, such as answering services. Japan had 290,000 employees, excluding value-added network services provided by type II carriers. Germany had 198,000 employees, France 146,000, and the United Kingdom 240,000. The German and French figures exclude the cable TV business. All of French and German employment is in France Telecom and DBP Telecom, respectively. About 97 percent of U.K. employment is in British Telecom, and about 95 percent of Japanese employment is in NTT and its subsidiaries.

\section{Productivity Measures}

We used two alternative measures of output for the industry, based on the number of calls and the number of access lines. The number of calls (allowing for distance) is the measure of output that the BLS uses for its productivity estimates for selected industries. In 1989, 457.6 billion calls were made on the U.S. network, using 129.1 million access lines-3,545 calls per line. In Japan 1,373 calls were made per line, in the United Kingdom 1,239, in Germany 1,101, and in France 870 .

BLS uses only the number of calls as its output measure, but we felt it was appropriate to view the number of access lines as a component of output, independent of the number of calls. Like an insurance policy, a telephone line can have value even when it is not actually being used. 
Figure 7. Productivity in Telecommunications in Selected Countries

A. Labor productivity index

Percent

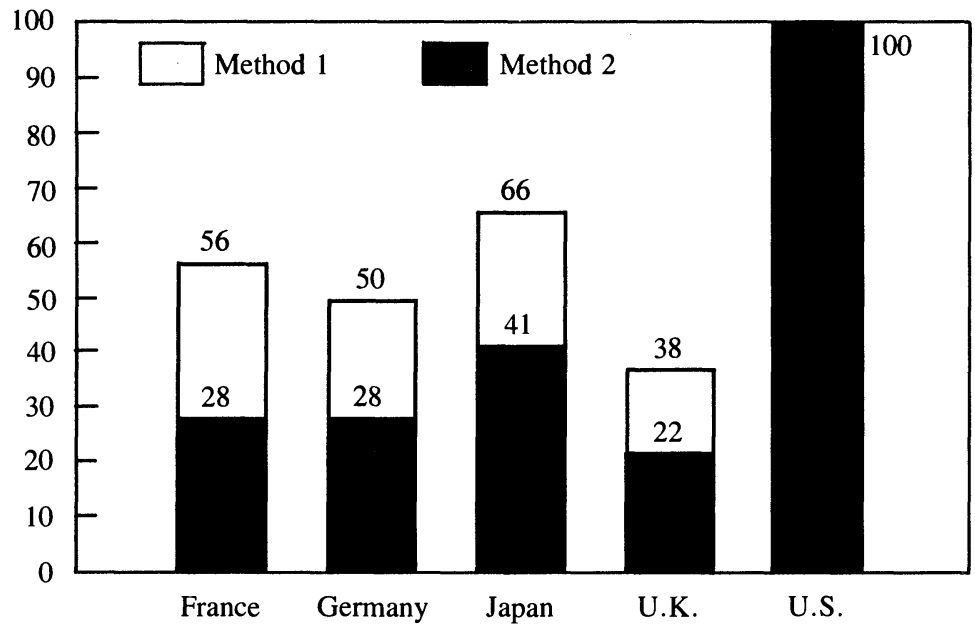

B. Total factor productivity index

\section{Percent}

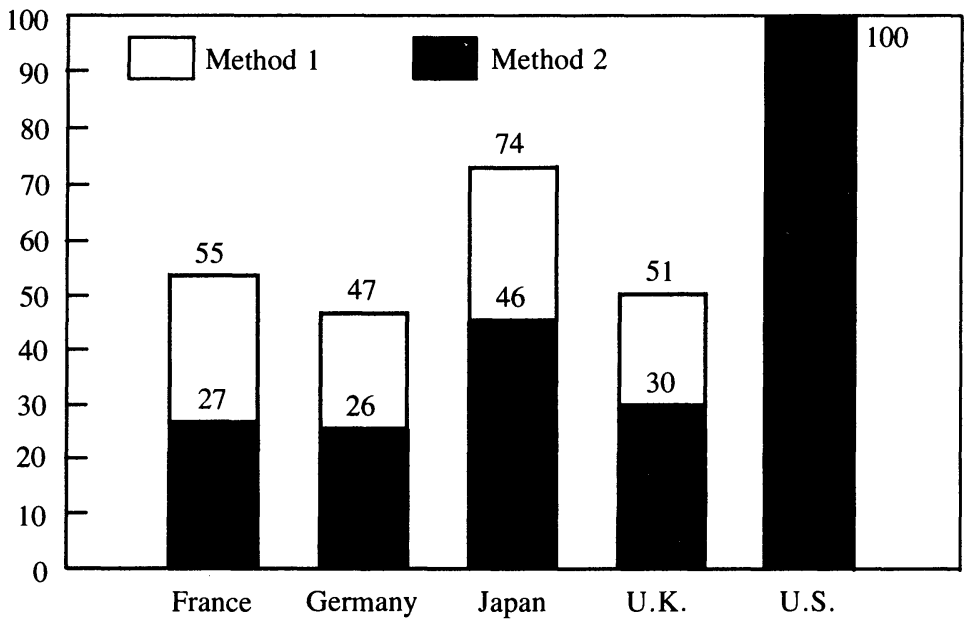

Source: Author's calculations. Method 1 weights number of calls and number of access lines, 50-50. Method 2 counts only the number of calls. 
The difficulty is that there are no meaningful revenue share measures to indicate the relative importance of the two output measures.

In figure $7 \mathrm{a}$, I show two alternative relative labor productivity calculations. The larger numbers for European and Japanese productivities are based on a 50-50 weighting for number of calls and number of access lines. The smaller numbers are based purely on number of calls. On either basis, labor productivity was much higher in the United States than in the other countries. The gap is huge if output is measured only by number of calls.

Capital is a very large part of total factor input in the telecommunications industry, so an estimate of total factor productivity for this industry seemed particularly important. Using capital expenditure purchasing power parities (PPPs), we found that France, Germany, and the United States had similar capital-labor ratios, while Japan's was somewhat lower. The United Kingdom's ratio was less than half of the U.S. value. The resulting total factor productivity estimates are shown in figure $7 \mathrm{~b}$.

It should be noted that France, Germany, Japan, and the United Kingdom all have captive manufacturing sectors, which makes these comparisons suspect as measures of the "real" capital stocks. I will say more about the role of capital and technology later.

In the case of telecommunications, the methodology used to compute productivity did influence the results. In particular, the outcome appears to depend on the judgment made about the relative importance of calls and access lines. ${ }^{49}$ Because the pricing of access and calls is heavily

49. In the McKinsey study, a weight of 85 percent was given to number of access lines. Because both Japan and France have more access lines per employee than the United States does, this weight led to estimated relative productivities that were as high or higher in Japan and France as in the United States. This weighting of the two outputs was based on an estimate that about 85 percent of employment in this industry is associated with installing and maintaining the network and 15 percent with handling the calls. The McKinsey study also made an estimate of total factor productivity for the industry, and the approach used weighted the "number of calls" measure of output much more heavily than it had been for the labor productivity estimates. This meant that the estimates for relative total factor productivity showed the United States far ahead of the other countries.

In preparing this paper, I was not persuaded that the 85-15 split for labor productivity had been correct. Operator assistance, directory assistance, customer inquiries, and complaints are all likely to be related to the number of calls, and these employees had not been included in the 15 percent. In addition, the inconsistency in the output measures 
regulated or controlled in all of the countries, the market offers no clear guidance on the correct way to make such an assessment. Nevertheless, U.S. relative productivity (both labor and total factor) is high in this industry, provided a reasonable weight is given to the number of calls made. ${ }^{50}$

This conclusion has been confirmed by calculations made in 1990 and sent to me recently by Henry Ergas for telecommunications in the United States, several European countries, and Australia. Strikingly, this confirmation occurs even though the productivity measure used is " 'main lines per employee, adjusted for contracting out." Ergas and his coauthors find the United States to have the highest productivity, followed by Sweden, Denmark, France (72 percent of United States), Spain, Canada, the former West Germany (58 percent), the United Kingdom (52 percent), and Australia. ${ }^{51}$

\section{Reasons for the Productivity Difference}

The telecommunications networks of the countries under study are very different. The characteristics of the networks that are likely to affect the number of access lines per employee are scale, growth in size, network density, network architecture and organization, and technology.

We tested for the effects of these factors on access line productivity using a simple cross-sectional regression analysis on fifty local operating companies in the United States. We ran separate regressions for three different measures-access lines per employee, access lines per operational employee, and access lines per dollar of operating cost. These indicated that scale (millions of access lines); growth (percent increase in number of access lines); and density (access lines per mile of cable) had an insignificant effect on these productivity indicators.

used for labor and total factor productivity meant that the normal relation between the two productivity measures did not hold. In particular, there was no evidence that the United States generally had a lower capital-labor ratio than did the other countries. I therefore recomputed the labor and total factor productivity estimates as described in the text.

50. Both Kenneth Flamm and Robert Crandall of Brookings have argued to me that using number of calls understates the U.S. relative productivity. Calls are longer in the United States, tying up switch capacity, and increasing numbers of calls are being made through private networks that are not counted in FCC data.

51. Ergas, Ralph, and Sivakumar (1990). 
Scale seemed to reduce productivity, if anything. We did find that network architecture (access lines per switch) affected productivity (more lines per switch raised productivity), as did technology. Operating companies that spent a large fraction of their switch expenditures on analog electronic switches (replacing mechanical switches) raised productivity. Companies that invested in digital switches suffered at least a temporary reduction in productivity, however. The results are shown in table 3.

We concluded that technology played an important role in affecting the number of access lines per employee across the countries. In particular, the low productivity of the German and U.K. systems is attributable in part to the slowness with which these countries have moved to electronic switches. Japan and France have adopted modern technologies and achieved about the same level of access lines per employee as has the United States. One can argue that France has overinvested in digital switches, especially given that they were produced by the expensive captive supply industry in France.

One obvious source of productivity difference results from the much higher level of phone utilization in the United States. As we saw earlier, the number of calls per access line is several times as high in the United States as it is in the other countries. Because of its private ownership and the flexibility of regulation, the U.S. industry has kept the consumer price of both local and long distance calls much lower than it is in other countries. Taylor has found high elasticities of demand for calls, and so the low prices have generated high demand (figure 8 ). ${ }^{52}$

Estimated price elasticities are probably not enough to explain fully the huge differences in phone utilization. Americans appear to have a higher propensity to phone, but that propensity may simply reflect the very long-run effects of the pricing strategy. The propensity to use the phone would rise over time if prices fell.

A second reason for productivity differences is the inefficiencies in the use of labor. Because the telecommunications industry in all of the countries is largely monopolized, the potential for slack in the organization of labor exists throughout. The British postal service was chronically overstaffed, and British Telecom had not reduced employment significantly by 1990 . The seven Bell operating companies in the United

52. Taylor (1980). 


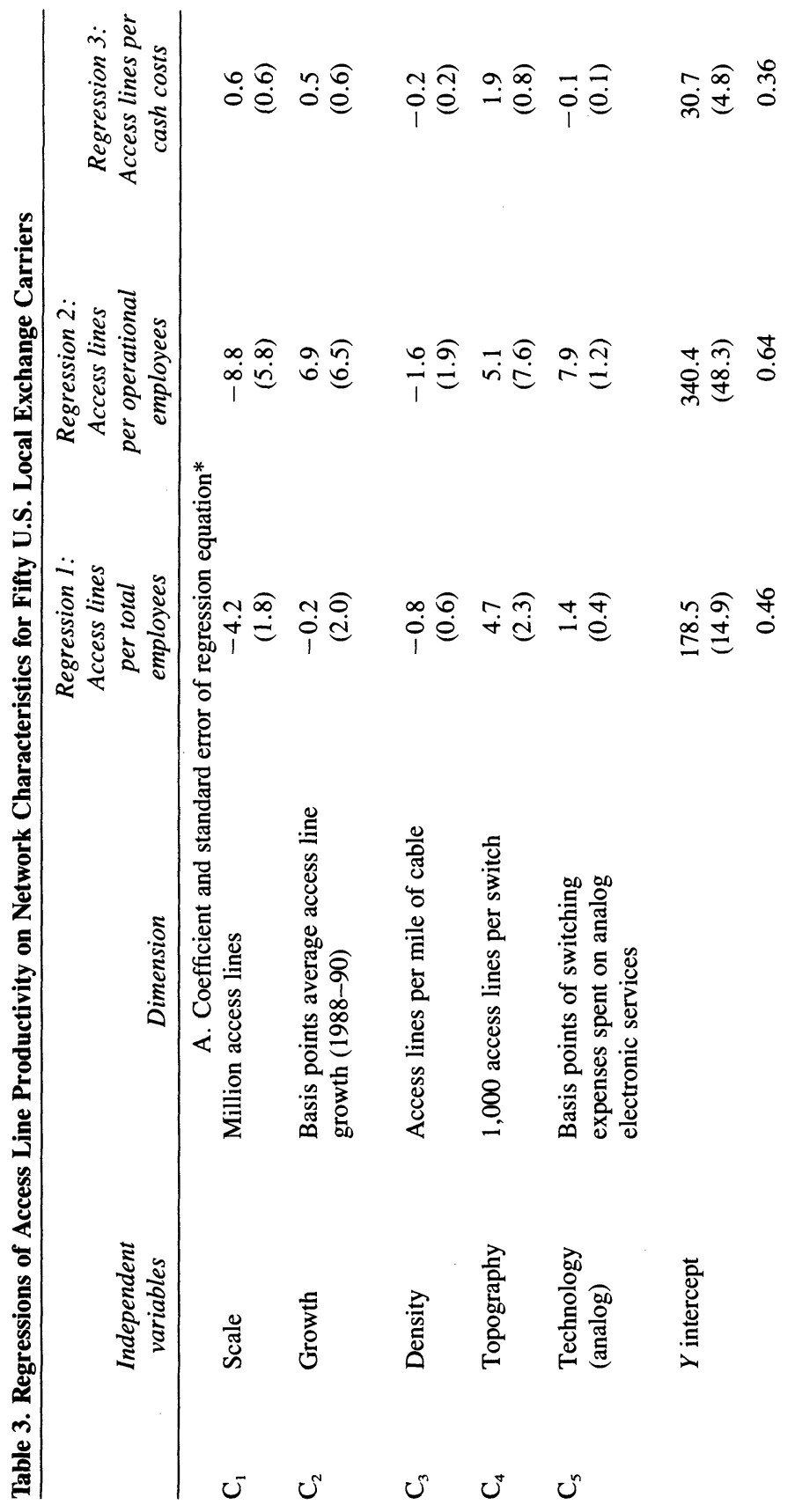




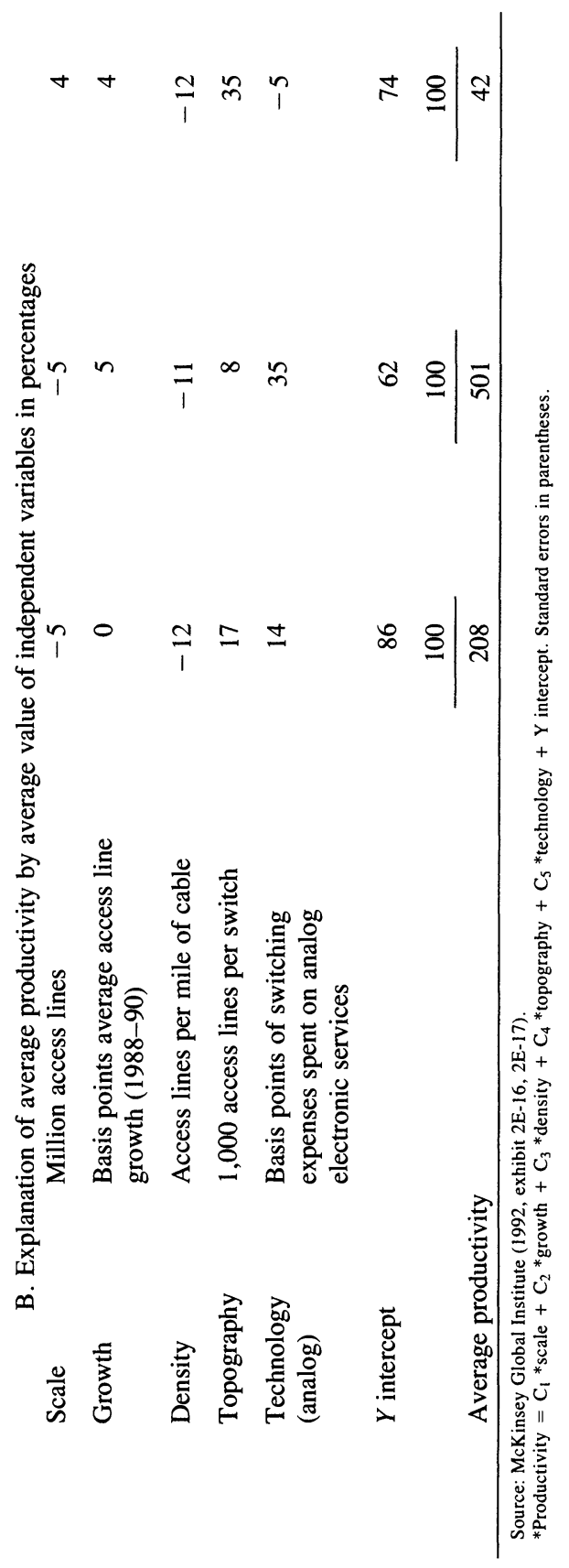


Figure 8. Price Elasticity of Demand for Telephone Service

Range, from different studies, of percentage change in demand in response to a 1 percent increase in price
A. Short run
B. Long run

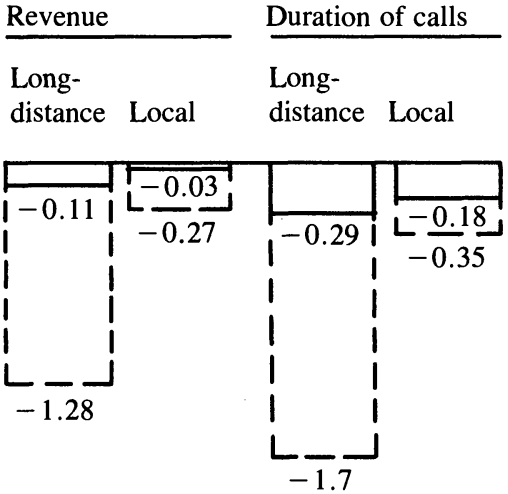

\begin{tabular}{ll} 
Revenue & Duration of calls \\
\hline $\begin{array}{l}\text { Long- } \\
\text { distance Local }\end{array}$ & $\begin{array}{l}\text { Long- } \\
\text { distance }\end{array}$
\end{tabular}

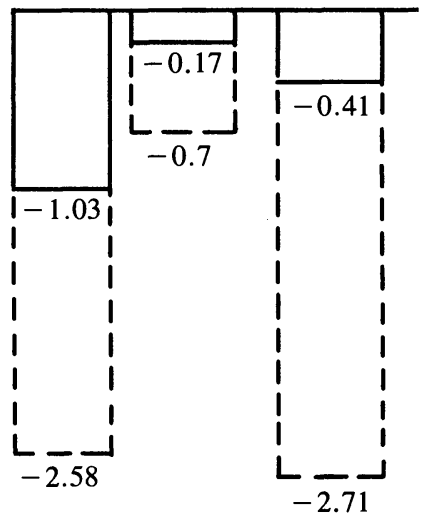

Source: McKinsey Global Institute (1992, exhibit 2E-25).

States have not reduced employment either, but AT\&T, facing a more competitive market, has sharply reduced its employment. NTT in Japan, facing potential competition from many new carriers, has also sharply reduced its employment.

The regulation of the pricing structure may have contributed to the failure of the Bell companies to reduce employment. For example, the local phone companies are not generally allowed to charge for directory assistance, leading to overuse of this service relative to an efficient market.

Differences among countries make an overall summary of the telecommunications industry difficult. A state-owned monopoly can achieve high productivity along certain dimensions of service if there is a well-financed technological push, as there was in France. Without such an effort, however, more adverse outcomes are likely. In Germany political pressure favors local equipment suppliers, thereby holding back the technology. And continuing political and union pressure to 
avoid layoffs also affects productivity negatively. The U.K. system was even worse than Germany's, and privatization has had only modest benefits so far. The Japanese industry was a state-owned monopoly with the advantage of a very strong domestic equipment supply industry. It may well be evolving into the most efficient system worldwide under the pressure of privatization and competition. The U.S. system has had the benefit of long-term private ownership but has not yet generated competition in basic local service. There is competition in cellular service and from private corporate networks, however, and increased local competition may be on the way.

\section{Retailing in France, Germany, Japan, the United Kingdom, and the United States}

Our basic sources of data for retailing in the countries we covered were the 1987 census of retail establishments for the United States, a similar but less comprehensive census by MITI for Japan in 1988, a biennial survey by the Central Statistical Office in the United Kingdom, and surveys by the Statistische Bundesamt in Germany and INSEE in France. These surveys provide information on full- and part-time employment in general merchandise retailing. We found that in Europe full-time retail employees worked forty hours a week and part-time employees about twenty hours. Part-time workers were therefore treated as equal to one-half of full-time workers in Europe. We concluded that "part-time", workers in Japan were working about forty hours, and so we counted all employment in Japan as full-time equivalents-a decision that might understate the number of hours worked in Japan. For the United States, we used BLS surveys to determine total hours and divided these by forty to estimate full-time equivalent employment comparable to that in Europe.

\section{Productivity Measures}

We were unable to find an ideal measure of output for the general merchandise retailing industry. The literature has proposed several alternatives, including sales, throughput (a measure of the volume of 
Figure 9. Productivity in U.S. General Merchandise Retailing, 1990

A. Value added plus rent per employee by market segment

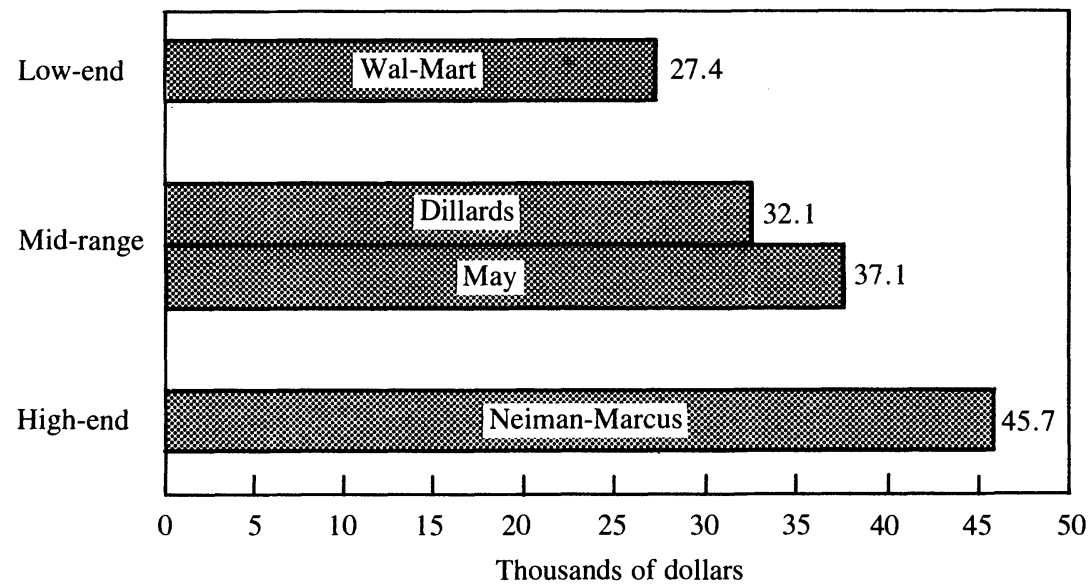

B. Total factor productivity ${ }^{\mathrm{a}}$

Percent

100

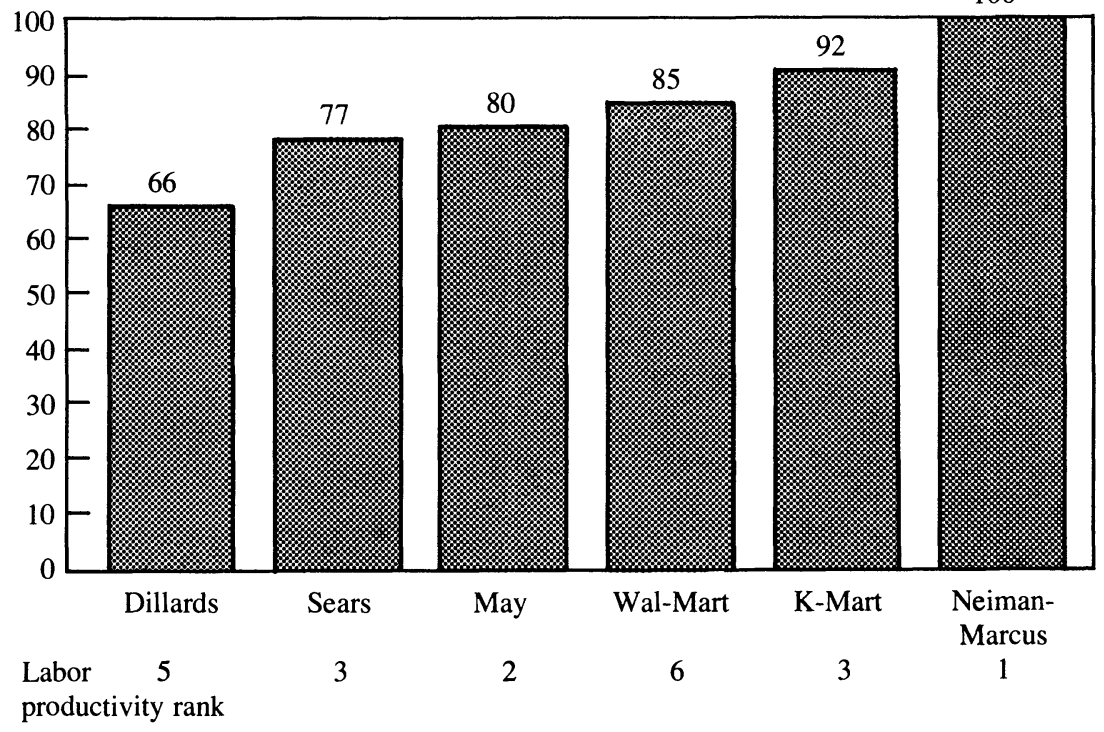

Source: McKinsey Global Institute (1992, exhibits 2D-7, 2D-8).

a. Index of labor and capital productivities. 
goods sold), value added, and others geared to indicators of consumer value. ${ }^{53}$

A retailer provides a location where customers can go to pay for and pick up merchandise, but it also provides information about the range of goods available and their prices and creates an ambience that affects the quality of the activity for the consumer. A warehouse store or a discounter provides a basic environment with linoleum floors and no decoration. Assistants are few and typically not very well informed. A successful upscale store provides a more pleasant environment and more assistants who are better informed and willing to spend time with customers.

In our judgment value added created at the retail level provides the best overall measure of output. Figures $9 \mathrm{a}$ and $9 \mathrm{~b}$ show how value added per employee and per total factor productivity (based on labor input and inventory only) varies for a selection of well-known stores in the United States. High-end stores such as Nieman-Marcus, that provide a lot of service, have high labor productivities, while low-end stores such as Wal-Mart have lower productivities. Part of the difference in labor productivity results from differences in the selection of goods provided. The estimate of total factor productivity, made using inventory capital, shows a somewhat different ranking than that for labor productivity. The remainder of the difference comes mostly from differences in the quality of the sales force. The high-end stores pay more and expect more qualified assistants.

Because we are counting only the number of full-time equivalent employees as the labor input, one would not expect to see a direct relation between productivity and profitability. The most profitable U.S. retail chain, Wal-Mart, does not have unusually high productivity using a value-added measure of output.

Based upon the census and survey data for each country, therefore, we were able to estimate value added per employee in national currencies for each of the countries under study. To compare across countries we needed an exchange rate, and we used the household consumption PPPs for the 1990 benchmark reported by the Organization for Economic Cooperation and Development (OECD). A broad PPP is needed

53. See Achabel, Heineke, and McIntyre (1984); Beckman (1957); Cary and Otto (1977); Goodman (1985); Ingene (1982 and 1984); and Ofer (1973). See also the discussion in the introduction of Griliches (1992). 
Figure 10. Productivity in General Merchandise Retailing for Selected Countries, 1987
A. Labor productivitya

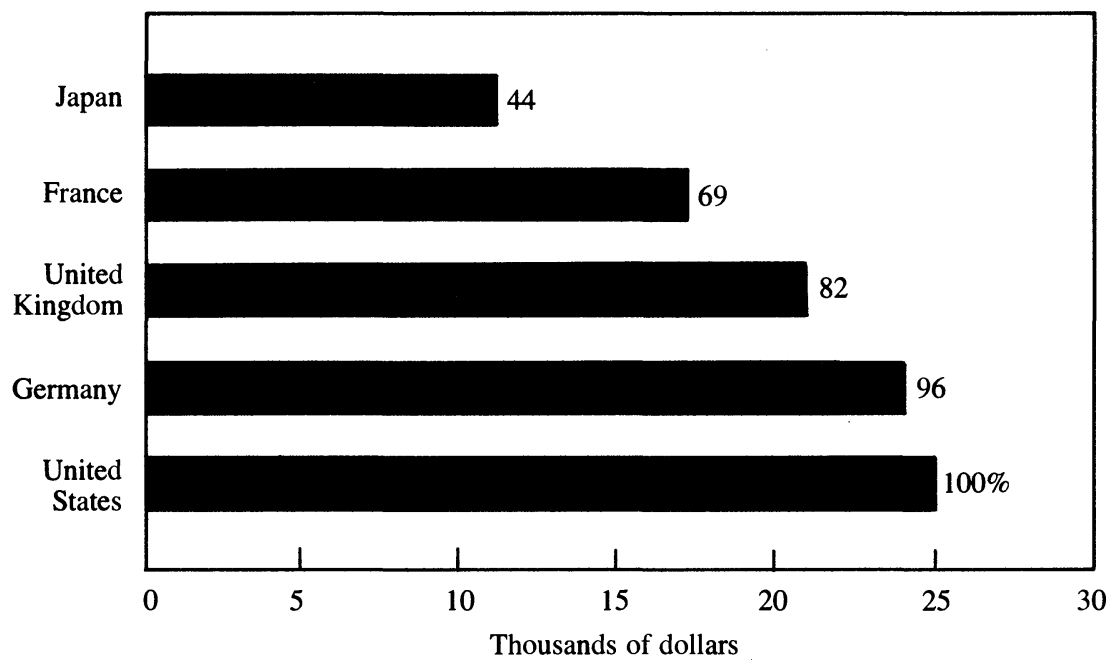

B. Total factor productivity

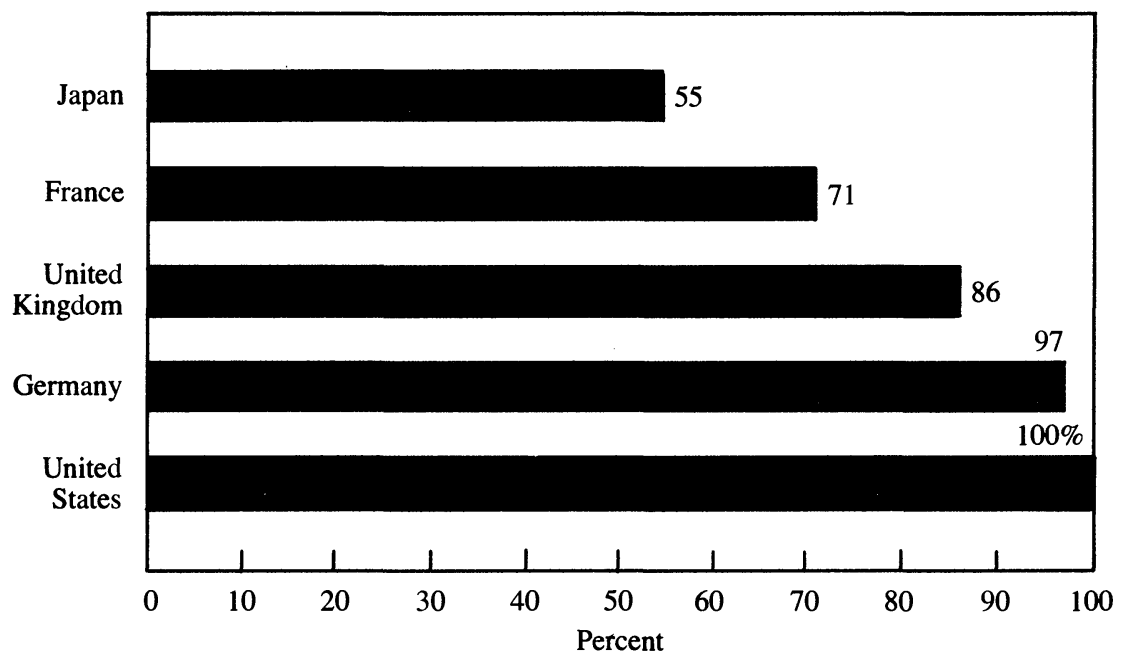

Source: McKinsey Global Institute (1992, exhibits 2D-3, 2D-5).

a. Value added per employee, converted at PPP.

b. Indexed values, 60 percent labor weighting. 
because retailers provide a broad range of goods. Some might argue that a narrower PPP based on nonfood consumption of goods would have been a better indicator of the items actually sold by general merchandise retailers. Because the 1990 benchmark PPPs impute a high price to U.S. education and health services, however, it is likely that the broader PPP understates U.S. relative productivity and does not change the overall thrust of the results reported here.

Figure 10 shows the results for value added per employee; the United States has the highest productivity, followed by Germany, the United Kingdom, France, and Japan. Japan's productivity is less than half of the U.S. level. The figure also shows an estimate of total factor productivity, ${ }^{54}$ which gives a very similar picture except that Japan moves up. Japanese retailers have small inventories relative to U.S. retailers.

\section{Reasons for the Productivity Difference}

The main driver of productivity in the general merchandise retailing industry is the structural changes that were described earlier. Most important, formats with high productivity have replaced those with low productivity. This process has happened to some degree in all of the countries that we examined, but it has moved more rapidly in the United States than elsewhere. Figure 11 shows the structure of store sizes in the five countries. It is notable that much of the retailing in France and especially Japan is in small establishments.

Within a given retailing format, productivity differences are less evident. We were told that productivity in a large department store is about the same in Tokyo, London, Paris, and New York. Figure 12 confirms this and shows that the same is not true for single category stores, where large stores such as Home Depot have much higher productivity than the small hardware stores available in Japan.

Another important structural change is that retailers, especially in the United States, have integrated backward into the wholesale level. For every wholesale employee, there are ten retail employees in the United States, compared with four or five in France and Japan. This integration in the United States, which has been facilitated by the shift

54. The total factor productivity is computed as a geometric average of value added per employee and value added per dollar of inventory, with a 60 percent weight going to labor productivity. This ignores structures capital. 

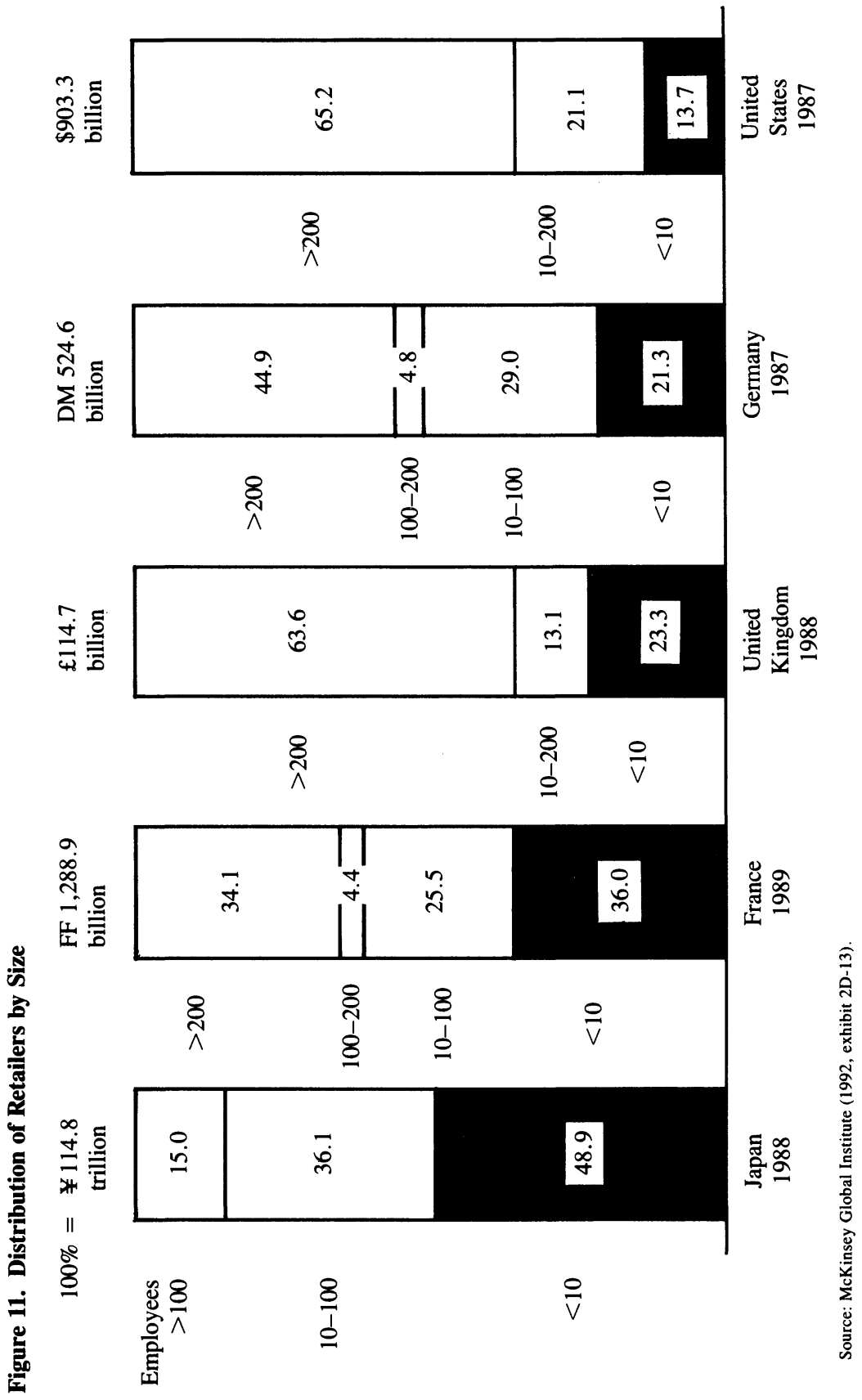
Figure 12. Productivity of General Merchandise and Specialty Stores, 1987-88

Thousands of dollars per full-time equivalent

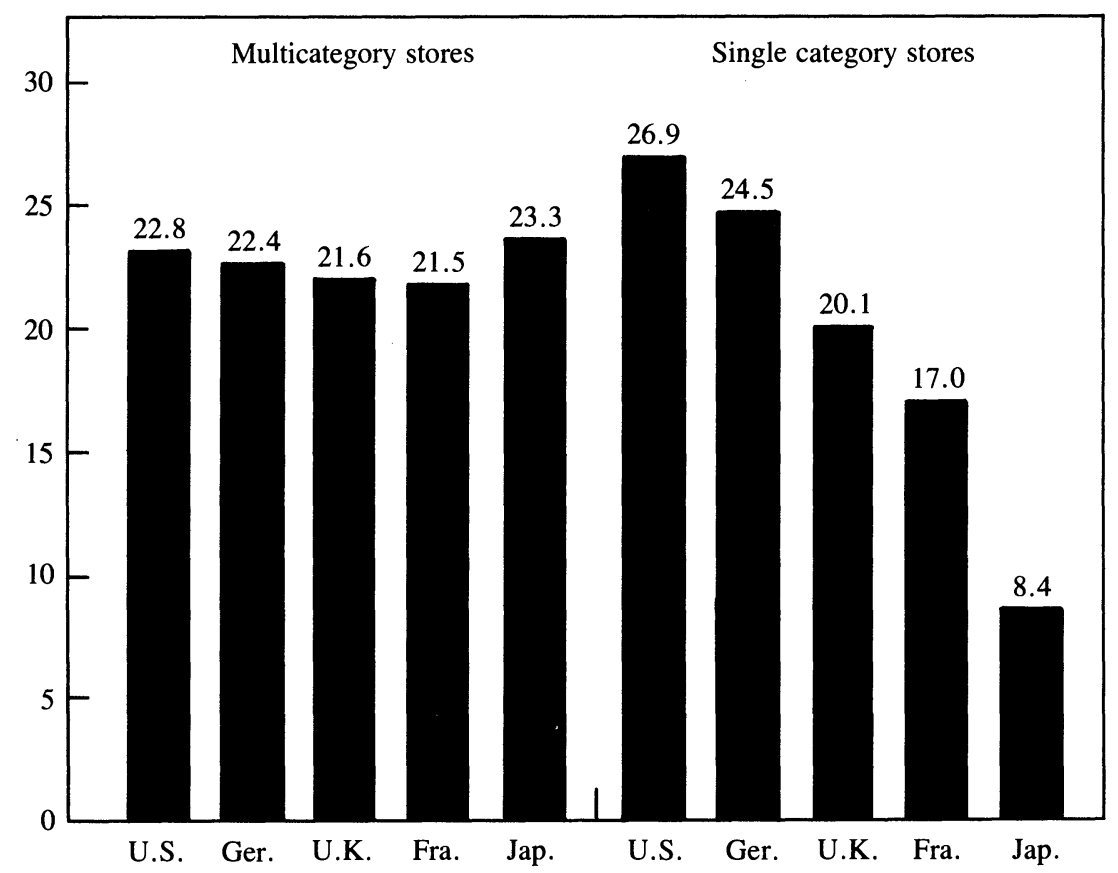

Source: McKinsey Global Institute (1992, exhibit 2D-16).

to large national chain retail establishments and by investment in information technology, has yielded a more efficient distribution system overall.

A final important difference in the productivity level is that the United States has more high-end stores than do the other countries, and as I noted earlier, high-end stores are more productive in value added terms. Even though Wal-Mart is considered the most successful retailer in the United States, it is not the highest productivity store. Highincome consumers shop in establishments that provide high levels of service, and the United States has more high-income consumers than do the other countries, especially Japan.

We concluded therefore that differences in the mix of output do provide a natural productivity advantage to the U.S. retailing industry and explain part of the productivity gap. More important, however, is. 
that regulation in Japan and Europe has slowed the structural adjustment of the industry, preventing more productive formats from driving out the less productive formats.

An anomaly in the overall results is the relatively high productivity in German retailing despite restrictive regulation. In part this reflects genuinely high efficiency. Regulation has not prevented the German industry from making the transformation to high productivity formats more fully than have Japan or the other European countries. Perhaps most important is that our output measure overstates the German relative productivity because of the inconvenience created by the short opening hours. Germans are forced to shop during working hours.

Robert Gordon and I once made a back-of-the envelope calculation that imposing German opening hours on U.S. shoppers would cost 3 percent of gross national product. ${ }^{55}$ That figure may have had some hyperbole in it, ${ }^{56}$ but even so, the long hours that U.S. stores are open, combined with the resulting slow sales volume per hour, surely puts U.S. retailers at a penalty. Gordon and I also argued that the increased diversity of products in U.S. stores has provided a form of hidden productivity increase, and most observers note the much smaller range of products available in German stores than in U.S. stores.

\section{Other Explanations of the Productivity Gap}

The central thesis of this paper has been that lower productivity in the service sectors in Europe and Japan indicates the adverse effects of inadequate competition and certain types of regulation on these markets. Two objections have been raised to the basic approach entailed in this hypothesis. The first argues that higher productivity in the United States does not result from any differences in the economic environment in Europe or Japan but is simply the residual effect of incomplete convergence. The second argument notes that differences in productivity occur among firms within a given market and asks why then would

55. Baily and Gordon (1988).

56. Many fewer women work in Germany than in the United States, so the penalty imposed by the short hours is lower in Germany. Of course, one could argue that we understated the effect. Limiting opening hours in the United States to the German level would bring on a consumer revolt. 
differences not occur among countries-the result of random differences. These two objections to the basic approach need to be addressed.

First, the convergence issue. The pattern of economic convergence among the major industrial economies after World War II is now familiar. The United States had by far the highest level of productivity in 1945, but Japan and the European economies were able to grow more rapidly in subsequent years than did the United States The drivers of the convergence process have been seen as, first, capital formation, which has gradually brought the capital-labor ratios in these countries close to the U.S. level (including human capital) and, second, the transfer of technology as these countries imported (and sometimes improved on) the most advanced technology, management methods, and product designs generated within the United States. ${ }^{57}$ Could it be that the observed productivity differences exist because convergence takes time and Europe and Japan are still lagging behind the United States?

The key question here is why has convergence in service industries been incomplete. After all, the war ended more than forty years ago, so one might reasonably expect that the convergence process would have run its course and that U.S. industries would no longer have any systematic productivity advantage over Europe and Japan.

It is hard to see capital shortage as a major reason for continued productivity differences. For the past ten years or more, international capital markets have allowed companies to finance investment even when the domestic flow of funds has been inadequate. High capital costs do not force service industries abroad to operate with lower capital intensities. Indeed, the conventional wisdom these days is that the low national saving rate in the United States has made the cost of funds higher in the United States than in Japan or Europe. ${ }^{58}$ In practice it is U.S. companies that have had difficulty finding domestic funds for investment and have borrowed internationally.

Complete convergence in terms of intangible capital should also have been expected. The technology embodied in capital goods and in the most important computer systems is available worldwide. And, at least

57. See Baumol, Blackman, and Wolff (1989) for an analysis of convergence.

58. See Hatsopoulos and Brooks (1986); Bernheim and Shoven (1987); Friend and Tokutsu (1987); Ando and Auerbach (1990); and McCauley and Zimmer (1989). For a countervailing view that the cost of capital is about the same in the United States and Japan, see Kester and Luehrman (1992). 
for production workers, it is often argued that skill levels are as high or higher in Europe and Japan than in the United States.

Most important, however, is the fact that the case studies themselves have found that gaps in capital intensity or technology do not appear to be the most important drivers of the productivity gaps. Moreover, in situations where U.S. companies have used more capital-intensive techniques of production or more advanced technology than other countries, it was usually because regulation in the other countries prevented the natural evolution of their industries.

In sum, to the extent that convergence is incomplete, it results from problems in the competitive and regulatory environments. A catch-up or convergence is possible, even likely, in the years to come. Indeed, rapid changes have taken place in some service industries in Europe and Japan since 1990. But these changes have been driven largely by changes in the regulatory and competitive environments, rather than by a sudden change in factor prices or access to technology.

The strongest response to the second objection-the possibility of random differences-is the case studies of service industries. In four out of the five service industries examined in the McKinsey study, the United States had a substantially higher level of labor productivity than the comparable European or Japanese industry in 1989 or 1990. This does not look like a pattern that has resulted from a random allocation of good and bad companies across countries. I see no reason why by chance so many of the most productive service companies should be of U.S. origin. In fact we know that this is not the case, because some of the companies operating productively in the United States originated in Europe.

I have spelled out the specific features of the competitive environment in the countries that adversely affected productivity. It is no accident that regulatory barriers to improved productivity have been created. The economic theory of regulation suggests that special interests capture the regulatory process, and surely some of that has been at work, particularly in protecting the interests of small business.

In addition, high relative productivity can usually only be sustained by a competitive environment where companies are free to enter and to fail and to lay off workers and restructure industries. These processes disrupt individual lives and result in large gains and losses of human, financial, or physical capital. Many U.S. airlines failed, for example, 
and many workers lost their jobs when the industry was deregulated. Many small towns and large cities in the United States have seen the retail base of their central business districts disappear as new retailers and retail formats have entered in the suburbs. Overall, employment in retailing and the airlines is probably higher as a result of these structural changes, because higher productivity lowers prices and increases output, but individual jobs and companies are disrupted, and for many countries such disruptions are unacceptable. In these countries the political and social decisionmaking process has opted for greater stability at the micro level-at least, temporary stability - at the price of lower productivity.

\section{Conclusions}

The existence of slack in privately held companies may be important in practice, and maximizing principles need not be abandoned in order to embrace this idea. Managers may prefer a comfortable oligopoly to the relentless pressure of competition and change. And even when there is no state ownership, governments may be able to pressure companies to avoid layoffs and thereby encourage slack. The case study of banking supports the idea that there is slack and that available innovations may not be adopted without the pressure of competition. The case studies of airlines and telecommunications point to the double danger of low competitive intensity and state ownership.

When regulation prevents structural adjustment of an industry, the productivity price can be very high. The restrictions on Japanese retailing provide a good example of this phenomenon.

The case study of telecommunications suggests that privately owned, price-regulated monopolies perform better than state-owned monopolies. Full-scale competition for telephone service can be expected to perform even better.

It is possible that a given productivity gap between the United States and other industrial countries in service industries could simply reflect the incomplete working out of the convergence process. I have argued that the speed and completeness of convergence depends on the economic environment. Incomplete convergence in service industries results from the competitive and regulatory environment. Because of 
political opposition to structural change, policymakers have allowed established economic interests to avoid change. Oligopolies have been tolerated or even encouraged in the (alleged) interests of overall economic stability.

This study supports the idea that competition encourages efficiency, but it also suggests that care must be taken in assessing the extent of competitive pressure. Monopolies or oligopolies that are sheltered by regulation are clearly bad for productivity. But industries with many small firms whose market shares are preserved by regulation are also bad for productivity. The small firms are unable to take advantage of economies of scale and lack the resources to innovate. In comparison, a dynamic oligopoly with many competing firms appears to have advantages. ${ }^{59}$

Competitive industries evolve in ways that often lead to losses for existing economic interests. If policy prevents this evolution, it can inhibit productivity increase and leave an industry's productivity level well below worldwide best practice.

This study has looked at cross-sectional evidence across countries. There is also, of course, time series evidence from the effect of deregulation in the United States and econometric studies of the effect of competition on performance. This is not the place to undertake a detailed analysis of this evidence, but my reading is that although the evidence does not all point in the same direction, it provides general support for the view that deregulation and competition encourage efficient production and enhance productivity growth ${ }^{60}$ For example, U.S. railroads doubled labor productivity after deregulation in 1980. British Airways has rapidly increased its productivity since being privatized and competing directly with U.S. airlines. And the U.S. auto industry has been forced to make huge adjustments in response to increased Japanese competition.

It would be useful in future research to add more of a time-series dimension to the analysis given here. Perhaps we will be able to recompute our results in a few years and see how the industries have evolved in response to the changing regulatory and competitive environments, such as the integrated market in Europe and the liberalization pressures in Japan.

59. This is not a new idea; see F. M. Scherer (1980) on industrial organization.

60. See Winston (1993). 


\section{Comments and Discussion}

Comment by Robert J. Gordon: Martin Baily's paper on productivity differences in selected service industries of the United States, Japan, and several major European countries is innovative and important. ${ }^{1}$ It raises interesting questions not just about the four industries that are studied as a whole, but also about broader issues in productivity research. Let me begin with a broad perspective, then turn to the paper itself, and, finally, return to the agenda of research puzzles that is suggested by this paper.

\section{Perspectives on Productivity Research}

From an American perspective productivity research has been dominated by time series studies using U.S. data, which can all be regarded as following up on Solow's seminal 1957 paper. The key contributions were Kendrick's monumental 1961 book, in which he built on industry studies developed by Kuznets and others at the National Bureau of Economic Research in the 1950s to develop industry-level data going back to 1870 , and Denison's growth accounting studies, which introduced systematic adjustments for labor quality and other intangibles. ${ }^{2}$

1. Baily's paper distills four of the five case studies in the McKinsey study, excluding restaurants, and it also excludes the McKinsey overview of cross-country productivity comparisons in aggregate data. Baily also adds his own interpretations, going beyond the McKinsey report. In calling the paper innovative and important, I refer to the project as a whole, and in this and further comments below, I make only scattered attempts to distinguish which interpretations are those of the McKinsey authors (where Baily was one of a team) and which are those of Baily himself. Accordingly, I often refer to the McKinsey-Baily study.

2. Solow (1957); Kendrick (1961); Denison (1962, 1985). 
A skeptical view would point out that this line of research has left us roughly where we began-just as Solow attributed relatively little of aggregate growth in labor productivity to capital accumulation and most to mysterious "'residual," so Denison in his last published book on growth accounting attributed most of the post-1973 U.S. productivity slowdown to the residual. ${ }^{3}$

The main tension in U.S. time series research has been between Denison and Jorgenson's research, including the latter's collaboration with Griliches in the 1960s. ${ }^{4}$ Jorgenson went well beyond Solow in anchoring his research in the formal economic theory of production, and (especially in his papers with Griliches) he scored many points of lasting value, particularly in the weighting of structures and equipment by user cost measures and in the use of near-ideal index numbers such as the Divisia to replace the flawed official data that use a single base year. The effect of Jorgenson's research has always been to increase the share of labor productivity growth attributable to capital accumulation and reduce that attributable to the residual.

Even though the research on the causes of the productivity slowdown is inconclusive, a few interesting negative conclusions have emerged. The most important is that capital accumulation is not the answer. Jorgenson's research upgrading the importance of capital accumulation relative to the residual and the related research of De Long and Summers in positing supernormal returns to equipment investment not only provide no help in understanding the puzzle, but actually deepen the puzzle. ${ }^{5}$ Because investment in equipment has grown so fast in the United States during the last three decades, the higher the weight attached to equipment (as Jorgenson or De Long and Summers would have it), the greater the slowdown in multifactor productivity (MFP) growth in the American economy.

In the past decade, spurred by the new growth theories of Paul Romer and followers, the big topic in productivity research worldwide has shifted to the issue of convergence ${ }^{6}$ A striking similarity between the Baily and the van Ark-Pilat papers is that almost all of the results are

3. Denison (1985).

4. See, for example, Jorgenson and Griliches (1967) and the critique of their paper by Denison (1972).

5. De Long and Summers (1991).

6. Romer (1987). 
presented as ratios of performance in some country to that in the United States. Even though these papers often generate interesting new data, not a single table presents growth rates of productivity in the United States. This appears to be an unfortunate side effect of the new growth economics, diverting attention from the growth rate of the frontier country to the rate of convergence to the frontier. But the standard of living of the world's population depends on both, not just one or the other. Surely, a scenario with a growth rate of 3 percent in the United States and 5 percent in Europe and Japan is preferable to an alternative scenario with respective rates of 0 and 2 . Yet these two regimes will be considered indistinguishable in the presentation of these two papers. And so I am not convinced by the argument at the beginning of the Baily paper that the key issue is to understand differences across countries in productivity levels.

The focus on levels leads to a more substantive problem: both papers leave the impression that the United States is doing well. This is especially true in the Baily paper, which paints a rosy scenario of an America with a virtually impregnable advantage over Europe and Japan, both enmeshed in giant cobwebs of regulation and other impediments to competition. Such optimism is somewhat startling to one accustomed to lamenting the slow growth rate of U.S. productivity. Accordingly, I begin by throwing some cold water on the optimists, in the form of the growth rates in table 1 . It is hard to be cheerful. In the top section the 1973-90 growth rate of U.S. average labor productivity (ALP) for the aggregate economy is only 63 percent of Britain's ALP and less than half, 46 percent, that of France's. ${ }^{7}$ The bottom two sections of the table refer only to the manufacturing sector and provide growth rates of ALP and MFP, based on the data that van Ark and Pilat use to compute their productivity levels. ${ }^{8}$ For comparability with the other countries, the second column recalculates the U.S. growth rates by omitting the effect of the hedonic price index for computers, because other countries do not use this method for deflating computer output

7. This poor performance comes despite my upward revision of the official U.S. data to correct for the bias intrinsic in using a fixed 1987 base year for output measurement. See the notes to table 1 .

8. I am very grateful to Bart van Ark for providing all the data in the bottom two sections of table 1; they are consistent with the productivity ratios presented in his paper in this volume. 
Table 1. Annual Growth Rates of Productivity Measures, Total Economy and Manufacturing, 1950-90

\begin{tabular}{|c|c|c|c|c|c|c|}
\hline $\begin{array}{l}\text { Productivity } \\
\text { measure }\end{array}$ & $\begin{array}{l}\text { United } \\
\text { States }\end{array}$ & $\begin{array}{l}\text { United } \\
\text { States } \\
\text { without } \\
\text { computer } \\
\text { deflator }\end{array}$ & Japan & France & Germany & $\begin{array}{c}\text { United } \\
\text { Kingdom }\end{array}$ \\
\hline \multicolumn{7}{|c|}{ Aggregate ALP } \\
\hline $1950-73$ & 2.8 & $\ldots$ & 6.8 & 4.3 & 5.9 & 3.0 \\
\hline $1973-90$ & 1.2 & $\cdots$ & 3.0 & 2.6 & 2.1 & 1.9 \\
\hline \multicolumn{7}{|c|}{ Manufacturing ALP } \\
\hline $1950-73$ & 2.78 & 2.78 & 9.38 & 5.94 & 6.03 & 4.20 \\
\hline $1973-90$ & 2.27 & 1.87 & 5.07 & 3.80 & 2.72 & 3.67 \\
\hline \multicolumn{7}{|c|}{ Manufacturing $M F P$} \\
\hline $1950-73$ & 2.18 & 2.23 & 5.47 & 4.37 & 4.55 & 3.03 \\
\hline $1973-90$ & 1.46 & 1.07 & 2.44 & $2.27^{\mathrm{a}}$ & 1.78 & $2.35^{\mathrm{a}}$ \\
\hline
\end{tabular}

Source: Aggregate average labor productivity (ALP) for the United States comes from the Economic Report of the President (1991, table B-46, p. 338; 1993, table B-44, p. 398). The 1973-90 growth rate is raised from an official figure of 1.0 to 1.2 to correct for 1987 base-year bias; see Young (1992, table A, p. 36), where 0.2 is the weighted average of the growth rates shown in column 5 for the period 1973-90. For other countries the 1950-73 rates are derived from output, employment, and hours per employee data taken from Maddison (1989, tables B-3, C-7, C-8); the 1973-90 rates are from Organization for Economic Cooperation and Development, OECD Economic Outlook 52 (December 1992: table 55, p. 151), where the growth rates shown for France and the United Kingdom refer to 1973-91.

Average labor productivity for manufacturing in the United States comes from the van Ark-Pilat paper in this volume (see data appendix). The computer adjustment is calculated by computing the real output of nonelectrical machinery using the implicit deflator for durable manufacturing. For other countries, average labor productivity growth rates were provided by van Ark, to be published in van Ark (forthcoming).

Multifactor productivity (MFP) growth rates were provided by van Ark, to be published in van Ark (forthcoming), with capital input for Germany, Japan, and the United States coming from the data appendix in the van Ark-Pilat paper and the share of labor compensation coming from the notes to table 7 of that paper.

(specifically, it substitutes the price deflator of durable manufactures for the price deflator of the subindustry that manufactures computers) ${ }^{9}$ In the bottom line adjusted U.S. manufacturing MFP growth for 197390 is less than half of that in Japan, France, and Britain.

Could some sort of inconsistency in the data reconcile the rosy view of the United States based on the ratio comparisons in the Baily and van Ark-Pilat papers with the dismal story told by the growth rates of table 1? A search for possible inconsistencies motivates table 2, which assembles all the data in both the Baily and van Ark-Pilat papers so that problems might be discerned. The top line is from the first chapter

9. I am not suggesting that the U.S. hedonic price index for computers is inappropriate, only that it is easier to calculate consistently measured cross-country productivity growth indexes by omitting the effect of the U.S. computer price index instead of guessing what would have happened if other countries had compiled hedonic price indexes for computers over the same period. A comparison of computer deflators for twelve industrialized nations is contained in Wyckoff (1993, table 1). 
Table 2. Levels of Productivity Measures Relative to United States, Selected Years Percent

\begin{tabular}{|c|c|c|c|c|c|c|c|c|c|c|}
\hline \multirow{2}{*}{$\begin{array}{l}\text { Productivity } \\
\text { measure }\end{array}$} & \multicolumn{2}{|c|}{ Japan } & \multicolumn{2}{|c|}{ France } & \multicolumn{2}{|c|}{ Germany } & \multicolumn{2}{|c|}{$\begin{array}{c}\text { United } \\
\text { Kingdom }\end{array}$} & \multicolumn{2}{|c|}{ Europe } \\
\hline & 1973 & 1989 & 1973 & 1989 & 1973 & 1989 & 1973 & 1989 & 1973 & 1989 \\
\hline \multicolumn{11}{|l|}{ Market economy } \\
\hline McKinsey ALPa & $\cdots$ & 49.0 & $\ldots$ & 93.5 & $\ldots$ & 86.0 & $\ldots$ & 75.5 & $\ldots$ & $\ldots$ \\
\hline $\begin{array}{l}\text { Backward extrapolation } \\
\text { using table } 1\end{array}$ & 37.4 & $\cdots$ & 70.3 & $\ldots$ & 68.7 & & 64.0 & & $\cdots$ & $\cdots$ \\
\hline \multicolumn{11}{|l|}{$\begin{array}{l}\text { Manufacturing } \\
\quad(\text { van Ark-Pilat data) }\end{array}$} \\
\hline Value added/hour & 49.2 & 73.9 & 62.7 & 82.0 & 79.7 & 83.8 & 52.4 & 61.9 & $\ldots$ & $\ldots$ \\
\hline MFP unadjusted & 63.7 & 81.0 & 66.8 & 76.8 & 81.5 & 83.3 & 52.9 & 66.8 & $\ldots$ & $\ldots$ \\
\hline $\begin{array}{l}\text { MFP with education } \\
\text { adjusted }^{\mathrm{c}}\end{array}$ & $\cdots$ & 82.4 & $\cdots$ & 75.0 & $\cdots$ & 84.2 & $\cdots$ & 69.1 & $\ldots$ & $\cdots$ \\
\hline $\begin{array}{l}\text { MFP adding structural } \\
\text { adjustment } t^{\mathrm{b}, \mathrm{c}}\end{array}$ & $\cdots$ & 84.6 & $\cdots$ & $\cdots$ & $\ldots$ & 78.7 & $\cdots$ & 69.2 & $\cdots$ & $\cdots$ \\
\hline $\begin{array}{l}\text { MFP adding size } \\
\text { adjustment }^{\mathrm{b}, \mathrm{c}}\end{array}$ & $\ldots$ & 96.3 & $\cdots$ & $\cdots$ & $\ldots$ & $\cdots$ & $\cdots$ & 68.1 & $\cdots$ & $\cdots$ \\
\hline $\begin{array}{l}\text { Adjustment to any } \\
1973 \text { ratio to omit } \\
\text { impact of U.S. } \\
\text { computer deflator }^{\text {d }}\end{array}$ & -7.8 & $\cdots$ & -7.8 & $\ldots$ & -7.8 & & -7.8 & & $\cdots$ & $\cdots$ \\
\hline $\begin{array}{l}\text { ervices } \\
\quad \text { (McKinsey exhibits) } \\
\text { irlines, kilometers per }\end{array}$ & & & & & & & & & & \\
\hline $\begin{array}{l}\text { employee (2A-4) } \\
\text { irlines functional }\end{array}$ & $\ldots$ & $\ldots$ & $\cdots$ & $\ldots$ & $\ldots$ & $\ldots$ & $\cdots$ & $\cdots$ & $75^{\mathrm{e}}$ & 90 \\
\hline$(2 \mathrm{~A}$ & $\ldots$ & $\cdots$ & $\cdots$ & $\cdots$ & ... & & $\ldots$ & & $\cdots$ & 72 \\
\hline Banking (2B-10) & $\ldots$ & $\ldots$ & $\ldots$ & $\ldots$ & $\ldots$ & 68 & $\ldots$ & 64 & $\ldots$ & $\ldots$ \\
\hline Restaurant & $\ldots$ & $\ldots$ & $\ldots$ & 104 & $\ldots$ & 92 & $\ldots$ & $\ldots$ & $\ldots$ & $\ldots$ \\
\hline Retail & $\ldots$ & 44 & $\cdots$ & 69 & $\ldots$ & 96 & $\ldots$ & 82 & $\ldots$ & $\ldots$ \\
\hline Retail MFP (2D-5) & $\ldots$ & 55 & $\ldots$ & 71 & $\ldots$ & 97 & $\ldots$ & 86 & $\cdots$ & $\ldots$ \\
\hline $\begin{array}{l}\text { Telecommunications } \\
\text { ALP (2E-9) }\end{array}$ & $\cdots$ & 97 & .. & 101 & $\cdots$ & 81 & $\cdots$ & 58 & $\cdots$ & $\cdots$ \\
\hline Telecommunications & & & & & & & & & & \\
\hline MFP (2E-11) & $\ldots$ & 77 & .. & 62 & $\ldots$ & 52 & $\ldots$ & 54 & $\ldots$ & $\ldots$ \\
\hline
\end{tabular}

Source: McKinsey Global Institute (1992); van Ark-Pilat data this volume.

a. McKinsey exhibit 1-7. Refers to 1988; uses average of 1985 and 1990 PPP benchmarks.

b. Ignores interaction effects. Adjustment for size and structure is based on employment weights.

c. Takes effect of adjustment for 1987 and adds it to unadjusted 1989 MFP. Adjustment for Japan is based on the comparison of general education levels. Other countries are based on vocational education levels.

d. Cumulates exponential growth rate of difference between adjusted and unadjusted U.S. manufacturing output growth, see table 1 .

e. Data for 1977. 
in the McKinsey study (not included in Baily's paper), displaying ratios of ALP in the four countries to the United States. Using table 1, one can extrapolate backward to 1973 and ask how much these countries have caught up. If France and the United States have maintained the 1973-90 growth rates since 1989, then France will achieve parity next year, in 1994. Germany will arrive in 2005, but convergence for Japan and the United Kingdom is nowhere in sight.

The next section of table 2 summarizes the manufacturing ratios from the van Ark-Pilat paper. ${ }^{10}$ The most striking result is that the fifth line for Japan, shows a ratio in 1989 of 96.3 , indicating virtual catch-up to the United States in manufacturing despite the much lower ratio of 49.0 for the entire Japanese economy. Catch-up is ten or more years away for the other three nations.

But there is a basic inconsistency in these numbers. The logic of weighted averages would suggest that if France and Germany are close to convergence in the aggregate economy but still well behind in manufacturing, then they must be at or above U.S. levels in nonmanufacturing. Yet this implicit conclusion is not supported by the bilateral productivity ratios created by the McKinsey report. The French are way behind in retail, and the Germans in banking and telecommunications. For Japan the problem is that the aggregate economy is so far below manufacturing that the implied ratio for nonmanufacturing must be around 30 percent, yet all the McKinsey numbers for Japan are well above this. If McKinsey is right, then ratios for the aggregate economy based on purchasing power parity (PPP) must overstate French and German output and understate that of Japan. Alternatively, if the PPP ratios are correct, then something is wrong with the McKinsey approach.

This is my first criticism of the McKinsey approach reported in Baily's paper. By stressing the case study method, the McKinsey team leaves the reader in the dark about the links with the aggregate evidence based on PPPs. Is the problem with the sectors that they do not cover, including construction, utilities, wholesale trade, and so on? Would it

10. The last line of the middle section indicates that any ratio relative to the United States for 1973 implied by the van Ark-Pilat data must be reduced by 7.8 percent to take account of the overstatement of U.S. manufacturing productivity growth resulting from the inconsistency that the United States has used a hedonic price index for computing equipment but that the other countries have not. 
not be possible to take PPPs for individual industries they cover and compute implied convergence ratios for comparison purposes? I am disappointed that the Baily paper does not move in the direction of filling in these holes left by the McKinsey report.

\section{Methodology: The Need for a Two-Sided Approach}

The Baily paper has two parts, an initial section that provides a detailed institutional description of regulations and other restrictions on competition for selected countries in four industries that account for about 13 percent of U.S. private, nonfarm, nonmanufacturing gross domestic product. A second part summarizes McKinsey's findings on productivity ratios relative to the United States for selected countries in these industries. Before continuing, let me make clear that I consider the McKinsey report to be a pathbreaking document, full of unique data and insightful observations. Yet it is not above criticism, and Baily's particular distillation of evidence from the report helps us to focus on some of the questions raised by its analytical approach.

The methodology laid out in the paper has three basic problems. First is the one-sided style of story-telling, in which all of the productivity problems are deeply inbred in other countries but not in the United States. Second is the inadequate connection between the institutional description and the development of the data on productivity ratios. Third are problems in the way in which the functional productivity comparisons are carried out.

To illustrate the first problem, the one-sided style, consider an alternative two-sided approach. In addition to describing the impediments to productivity in Europe, one could have developed a parallel institutional description of impediments to high productivity in the United States. That description could start with violent, gun-infested schools that inhibit mental concentration, low test scores in math and science, and large expenditures on security guards required by America's crimeridden society. It could turn next to the role of legal and illegal immigration in sending waves of unskilled workers to the United States, lowering wages for unskilled workers and fostering such productivityreducing practices as baggers at supermarkets and busboys in restaurants. It could go on to excess litigation, malpractice insurance, adversarial labor-management relations, and union intransigence on work 
rules and then conclude with insufficient and misguided regulation that fostered chaos in banking and financial intermediaries in the 1980s.

Having supplemented Baily's description of impediments to high productivity in Europe and Japan with a description of impediments in the United States, one could then turn to the evidence, where sixteen of the twenty-three McKinsey foreign-U.S. ratios in the bottom section of table 2 are below 90 percent. Does this imply that my list is wrong and Baily's is right? Or that mine is one-third right and his two-thirds right and that a weighted average of them should be taken? The methodology does not even consider these troubling questions, much less provide a road map to an answer.

The second problem, the lack of connection between the institutional description and the productivity ratios, is not inherent in the report itself but rather in the way Baily has proceeded. For instance, the report presents the case studies developing the productivity ratios first and then turns to examining possible explanations, which generally are broader than the competitive issues that Baily chooses to emphasize. The "synthesis chart" in the McKinsey report stresses as "important" several factors that go beyond competition, concentration, and government ownership (the factors stressed by Baily's paper)-namely, demand factors, management behavior, and organization of labor. Baily's list of impediments to competition in Europe and Japan is hair-raising, but why are U.S. restrictions on interstate banking not equally debilitating - they are briefly introduced and then dismissed as unimportant because the banking productivity ratios in Germany and the United Kingdom are so low. Why do U.S. impediments to competition matter less than German or British impediments to competition?

\section{The Functional Productivity Approach as Applied to Airlines}

The formal problem is to estimate cost functions and include as explanatory variables everything that matters for cost, including factor prices, and in the specific airline example, such structural variables as length of haul, length of hop, type of aircraft, number of pilots required for cockpits, and whether the flight is domestic or international. When those estimates are completed, there will be residuals, and if a panel data set exists, airline effects (that is, the coefficient on an airline 
dummy) can be estimated. If enough international data is available, country effects can be estimated. Once the ultimate residuals are turned up, a debate can ensue on whether they represent regulation, managerial efficiency, or something else.

As it happens, my undergraduate thesis was a functional cost analysis of the U.S. airline industry in 1961. ${ }^{11}$ Like McKinsey I divided cost into functional categories and tried crudely to control for the main determinants of cost by plotting costs for a given category against such control variables as length of hop (for aircraft operating costs) or size and type of airport (for costs of aircraft servicing). Even then, I found that the latter types of costs were higher at large airports than at small airports (whether or not the large airports were hubs). In much more sophisticated work, Caves and collaborators and Sickles have carried out this exercise properly, using modern production theory and statistical methods. ${ }^{12}$

In contrast with either my childhood effort or the sophisticated modern studies, the McKinsey ratios have no controls at all. Let us focus on a couple of the missing controls that are important for comparisons of the United States with Europe but that have nothing to do with government ownership or competition, the main themes of the Baily paper. Consider first the issue of international borders and language differences. International flights need more people to examine passports and weigh baggage at check-in, for security checks, and to handle passengers because of physical divisions within airports that inhibit cross utilization of personnel. Until European airports are rebuilt to make all intra-Europe flights and domestic flights arrive at a common set of gates and baggage claim areas, Europe will still have a productivity disadvantage, even if airlines are deregulated.

Then, take language. On a visit in 1990 I found that Lufthansa had two people working in a ticket office in Florence, Italy, servicing one flight a day. Not surprisingly, Baily's paper shows that Europe's worst functional productivity ratio is in "ticket and sales personnel.' Why doesn't United Airlines, which serves places such as Burlington, Vermont, and Billings, Montana, with two or three flights a day, have a

11. Gordon (1965).

12. Caves and others (1987); Sickles (1985). 
ticket sales office in those cities? Partly, it is because people can simply show up at domestic airports and get on a flight if there is room, whereas ticket changes on international flights require stickers and endorsements. But most of the difference must be due to language. German travelers in far-off Florence want the security blanket of a Lufthansa officer where they can speak German if they want to change their plans or reconfirm their reservations. U.S. airlines do all this with monolingual, continent-wide, toll-free numbers.

\section{The Treatment of Airlines}

The principle of comparative advantage suggests that I forgo any comments about the McKinsey-Baily treatment of the other industries and concentrate on other issues raised by their discussion of the airline industry. The red flag is raised immediately with the statement about the "hub and spoke system that the U.S. industry has developed since it was deregulated." Wrong.

By the late 1960s airports in Atlanta, Chicago, Denver, and other places had very large hubs, but they were missing spokes (because of route regulations that prohibited airlines from flying where they wanted), just like someone who has a fist fight and emerges with a lot of teetn missing. The similarity is most notable in Atlanta, where Delta and now-defunct Eastern Airlines together had some five hundred departures a day in 1978 before deregulation; survivor Delta in 1993 had roughly the same five hundred departures a day, and now they fill in all the spokes that were missing in each carrier's 1978 network. Before deregulation the favorite joke of southerners, at least until it became a cliché, was that "when a southerner dies and goes to heaven, he has to change planes in Atlanta.' One might add that because of the missing spokes, he or she also often had to change airlines, an inconvenience that deregulation has largely eliminated. So the first effect of deregulation was to fill in the spokes and virtually eliminate intercarrier connections.

The second effect was to allow the creation of medium-size hubs, some of which-including Charlotte, Houston, Newark, Phoenix, Pittsburgh, and Salt Lake City-are now as big as the original hubs formed before deregulation. Literally thousands of daily nonstop flights have 
been created for lucky residents within reach of these and other airports. This explains why the city fathers of medium hubs such as RaleighDurham and Nashville are so desperate to forestall the threatened closure of their hubs by American Airlines.

The most widely repeated misconception about airline deregulation is that nonstop flights were replaced by connections that forced passengers to troop through hubs on their way to spokes. Remarkably few direct flights were eliminated, and their number is swamped by the large number of new nonstop flights from old hubs, where the missing spokes were filled in, and, more important, from the new hubs. ${ }^{13}$

The Baily analysis of bilateral international route rights implies that somehow there is a logical link between these route rights and the apparent absence of hub and spoke within Europe. Yet European airlines are in a much better position to develop hub and spoke than U.S. airlines were to develop Chicago and Atlanta before 1978, because the Europeans control 100 percent of the bilateral route rights to their own hometown-London, Amsterdam, Frankfurt, or wherever. There is no regulatory reason for spokes to be missing, unlike the United States before deregulation. In fact, for decades KLM has run a hub and spoke operation in Amsterdam, constantly stressing in its advertisements that it provides the fastest flights from northern England and provincial Germany to intercontinental destinations.

To understand why more European airlines do not run their home airports as U.S. airlines do, or as KLM runs Amsterdam, one should look not to government regulation per se, but to capital costs, because bunching flights is much more capital-intensive than spreading them out. The basic reason why London Heathrow (featured in Baily's figure 4B) and Frankfurt have spread-out flight patterns is that they are constrained by lack of land, gates, and runways, and so the airlines are forced by tight slot controls to spread out their departures. In other European airports, not covered in Baily's charts, much more bunching occurs than in Heathrow or Frankfurt. Symmetrically, if Baily had

13. Most of the top five hundred domestic markets either had nonstop service in both 1978 and 1989 or did not have it in both of those years. Where there was a change, markets adding nonstop service outnumbered those losing nonstop service by a margin of sixty-one to seventeen. A complete census of routes shows an even more lopsided increase in nonstop service. See Gordon (1992, tables 10.7, 10.8, pp. 389-91). 
contrasted Heathrow, the largest European airport, with O'Hare, the largest U.S. airport and also equally slot-constrained, he would have found Chicago's arrivals and departures as spread out as London's. ${ }^{14}$

The basic reason for bunching in medium-size U.S. hubs, such as Minneapolis (see Baily's figure 4A), is simply geography, which has surely remained unaffected by deregulation. Before or after 1978, planes that take off from the East Coast early in the morning are all going to arrive at a mid-continent hub at about the same time in midmorning. Similarly, eastbound planes from the West Coast will all arrive at the hub around noon, as shown in figure $4 \mathrm{~A}$.

The true reasons for productivity differences among airlines can be found not by asking why some European airlines are not as productive as some U.S airlines, which is doubtless true, but by asking why most U.S. airlines are not as productive as Southwest Airlines (SWA). This airline has most large U.S. airlines scared to death, but they are unlikely to imitate SWA for two reasons. First, unions at most big carriers will not allow the flexible work rules that help SWA thrive, and, second, consumers will not stand for universal application of the rigid SWA production system, which achieves fifteen-minute turnarounds and high utilization of labor and capital, but only by prohibiting any transfer of luggage, even among its own flights. That may be fine for short hops, but not for grandma, who now has fifteen to twenty daily opportunities to fly via hub connection from Tucson to Charlotte or from Tampa to Oakland, each from an airline willing to transfer her baggage at a hub.

In short, SWA offers a different quality product from large U.S. airlines. Nothing in the McKinsey-Baily analysis indicates that their functional productivity ratios have been purged of analogous quality differences between European and U.S. airlines, including not only that reassuring Lufthansa ticket agent in Florence, but also the smoked fish platters served in economy class on 500-mile European flights in contrast to an empty tray in the United States. If quality differences are the key difference among airlines, then deregulation is not going to cause productivity in Europe to converge any more than fifteen years of U.S.

14. O'Hare's 1,200 daily departures are spread evenly at about eighty an hour from 6:30 A.M. to 8:30 P.M., about double the hourly rate at Heathrow, shown in Baily's figure 4. 
deregulation has created convergence between the costs and productivity of Southwest Airlines and American Airlines.

\section{Questions Raised for Further Research}

Space prevents comments on the other industries treated in the Baily paper. The right way to conclude is to ask questions about the McKinsey-Baily project that might provide an invitation for future research. Specifically, how can the imminent convergence of France and Germany with the United States, implied by the aggregate PPP data, be reconciled with the implication of the McKinsey-Baily analysis that convergence is still a long way away?

Several, more general questions are raised by these studies. How can broad-based tax incentives for investment be justified when the aggregate data provide no support for the view that slow capital growth has caused the productivity slowdown or that capital inadequacy has played any role in the low European productivity ratios revealed by McKinseyBaily? How can public support for education and training be justified when these detailed case studies deny that labor quality plays any role at all? How is public investment in higher education justified in view of widespread reports that recent U.S. college graduates are either unemployed or underemployed at jobs that do not require a college education?

One way to start is to recognize that trade-offs between the benefit of regulations to producers and unions on the one hand and the benefit of deregulation to consumers on the other are handled differently by different countries. The countries, notably Japan, make different political judgments. Economists at least can agree that they are not correctly measuring the benefits to consumer welfare or consumer friendly systems.

Finally, if the McKinsey report is saying that the ultimate difference between countries is in the organization of production by management (a point deemphasized by Baily), where does the view that management really matters fit in the economic analysis of production? Motorola, Intel, and Microsoft go up while IBM goes down. Chrysler and Ford go up while GM sinks. Japanese auto firms come to Ohio and Kentucky and produce automobiles, using supposedly undereducated American 
workers, and achieve a higher quality and productivity level than U.S. firms had earlier achieved with workers of the same objective characteristics.

Despite the implication of this paper, the Japanese do some things right and seem almost to have converged with the United States in the manufacturing sector. But the question why seems to reach far beyond the current agenda of productivity research. Sometimes I conclude, facetiously, that Japanese manufacturing does so well because Japan has no world-class business schools - that is just a taunt to help reorient the productivity research agenda.

Comment by Timothy F. Bresnahan: I will begin with an old joke. An economist comes to Washington and attends a policy meeting for the first time. After long and detailed discussions, the lawyers ask about the economics of the issues. The answer: "Competition is good.' But the lawyers want to know exactly how this applies to the specific policy issues under discussion. The economist: "Here, competition is very good.",

This has been an area in which economics as a discipline has sometimes been weak. Our staying power in specific policy discussions is sometimes undercut by a tendency to use powerful general arguments where specific local ones would be more convincing.

I want to start off with an accolade for Martin Baily and McKinsey for trying to have a little more staying power. They know the details of the industries about which they are writing, particularly the limits on competition in those industries, when they argue that "competition is good." They have obviously done a tremendous amount of hard work.

Nonetheless, I want to argue that this is really two quite separate and distinct papers. One of them is about international productivity comparisons in services. The other is about the wisdom of regulation. The interesting tables in the paper mostly go with the first paper, and Bob Gordon's discussion focuses mostly on it. I will concentrate mostly on the second, regulatory, paper.

Let me start by unpacking, just a little bit more, Baily's theory of why limits on competition might hurt productivity. That theory is rooted in a view of industries in general and service industries in particular, 
which I share. ${ }^{1}$ Industries are characterized by a great deal of heterogeneity across different firms in their organizational capability to deliver what people want. Limits on the geographical scope of competition mean that customers are not served by firms near the top of the distribution of talent overall but rather by the best local firms. Many customers are, therefore, badly served.

If there are scale economies-and economists continue to suspect that many of the service industries analyzed here have unexploited scale economies-then limits on the geographic scope of competition also prevent operations at efficient scale.

So geographic limits on competition mean that the typical customer is served by an inefficiently small firm and not by the best available firm. Baily observes that these restrictions will lead to low productivity levels and possibly even to low rates of productivity growth. This links this particular theory of the bad effects of regulation and the good effects of competition somewhat more directly to the traditional macroeconomics of growth than do other, more familiar arguments about regulation and competition. Baily proposes to investigate the impact of geographic limitations on competition arising from international differences in regulations primarily through examining international differences in productivity levels.

In focusing on this single observable outcome, Baily's method picks up both its strengths and its weaknesses, for these regulatory limits on competition do many other things besides. The implicit political economy of the paper is that regulators are engaged in transfers to local sellers by whom they are captured. If we grant regulators some other purposes, the limitations on competition (and the hit to productivity, if any) will be seen as an unhappy side effect.

I agree with Baily that this is a potentially important outcome of limitations on competition, whether caused by regulation or not. I am concerned, however, with the effectiveness of a research strategy for regulatory assessment based primarily on looking at productivity. It seems to be too far from the goals of the regulators, unless we assume that those goals are purely a transfer to sellers-in which case we can oppose the regulation without bothering to do the empirical work. 
Let me make that case in somewhat more detail in connection with telecommunications in the United States and Japan. I intend to paint a very different picture of telecommunications regulation in the two countries than that offered by the conclusions of this paper, building both on the paper's analysis and on previous analyses, notably by Roger Noll. ${ }^{2}$

Why are telecommunications regulated in large countries? Typically there are a variety of reasons. One is to finance the scale economies that have been thought to go with telecommunications systems and that are still thought to go with local telecommunications. A second goal is to finance technical progress in telecommunications, a dynamic scale economy. Clearly, either of these regulatory goals involves raising the general level of telecommunications prices.

A different regulatory goal has been redistribution of rents. Distribution comes into play early and often in telecommunications regulation. Through 1984 basically all of the governments of the United States and, afterwards all but the federal government have worked over the telecommunications system to try to achieve a set of transfers of rents from some classes of customers to others.

In particular, the U.S. system has been characterized by high prices for business services. The distributional goals have included not only transfers to residential customers as a class but also specific attempts to transfer to marginal customers such as rural residences. Universal connectedness has been part of the argument for this distributional scheme. This is a familiar if not entirely uncontroversial story.

Martin Baily's paper tells a very different story of how Japanese telecommunications regulations vary. Does Japan go to elaborate regulatory lengths to tax business in order to subsidize residential telecommunications customers? You bet not. Exactly the reverse. In Japan we see, absolutely characteristic of the way political economy in that country often works, attempts to tax the consumer's use of telecommunications to subsidize business use.

What is the effect of this regulatory difference? It leads me to a different explanation of why "functional productivity"' is different in the two countries. This business has increasing returns to scale, even at the national level, if the margin on which the scale is increased is the number of people who have phones and the frequency with which

2. See, for example, Noll and Rosenbluth (forthcoming). 
they phone. That broad access and those cheap residential calls in the United States lead to many calls and many telephone lines, that is, they lead to high $\mathrm{Q}$ and low AC, high measured productivity. In Japan, it is just the reverse.

That is my first point. There is a relationship here between regulatory differences and productivity, but it is unlikely that it comes from a univalent "more competitive", regulatory stance in one country than the other. Telecommunications, like many service industries, is a multiproduct industry. Often distributional regulatory goals involve tilting among the different products of the industry. The other goals of regulation may affect productivity measures in a first-order way, obscuring the effect through blocking efficient competition.

I took up telecommunications first because it would let me make each of my two main points. The other is to ask whether productivity is what should be measured to determine whether the regulatory regime makes economic sense.

Productivity is about the production side of the economy: here, making lines, making telephone services. That is not the only question to be asked if one is trying to understand efficient telecommunications regulation. If one believes that there are static or dynamic increasing returns in telecommunication, the question to be asked is the Ramsey pricing question-one nation's regulatory regime puts the high margins on one set of products, the other on another. Which is wiser? That is a question about the elasticities of demand, not about productivity.

Hoping not to sound like a defender of AT\&T, let me point out further that this has been a very technically progressive sector. You don't have to invent the transistor many times to pay for a lot of static welfare triangles.

Because of my relentless parochialism, I am ignorant of the facts in Japan. But I would be shocked to learn that MITI has not forced NTT to put a great deal of money into various general purpose technology initiatives, the fifth generation computer, and all that. I'd be shocked to learn that (if NTT is not vertically integrated backward into equipment) that NTT buys telecommunications equipment at anything like marginal cost. In short, I'd bet a lot that high telephone prices in Japan are being systematically used for mercantilist subsidy of technical progress in electronics.

Just as the transistor was only invented once, the sample size for 
assessing those mercantilist technology bets in Japan will be small. The recent ones were probably bad bets ex post for the Japanese. It turned out to be consumer electronics that paid off for them big time. Nonetheless, the question about the relationship between regulation as a form of subsidy to technology-intensive industry and the growth of productivity in the whole economy is an interesting one in connection with telecommunications. Again, it is essentially unrelated to the measurement of productivity in the industry itself.

Let me underline this general point by making it about airlines. Baily threatens, at the end of his paper, to turn from cross-section work to time-series work. One industry in which there has already been time series work on productivity and regulation is airlines. I am referring to Bob Gordon's work, which finds essentially that deregulation had no effect on productivity. Yet that was a piece of deregulation that had huge effects on all kinds of economically important variables. Price comes to mind. Although debate continues over how big the social gains were, they were not productivity gains.

I agree completely that most regulations imposing geographical limitations on competition have bad effects. The point is, there are other places to stand to assess the wisdom of those regulations, and productivity is not at all the obvious place to stand.

Let me turn to retail trade. This is one place that I want to get down into the details and worry about this paper's measurement method. Before I do, let me observe that in the service sectors only so much can be done to measure productivity correctly. Product quality issues and localization are so critical that it is hard to do a very good job. This paper works very hard, perhaps about as hard as current tools allow, on the measurement issues.

That said, I believe that there is considerable danger of confusing price with quality in using, as this paper does, value added as a measure of retail output. Retailers who have market power or valuable market niches will be marking up their products a great deal. That would be counted as real output in the framework of this paper. Consider automobile dealers. Using this paper's framework, they would be considered spectacularly productive, but I believe that it is all local market power. With that one caveat, I am done with methodology.

Let me now take up a few other points about the effectiveness and 
appropriateness of productivity as a welfare measure in thinking about the extent of competition in these industries.

In retail trade scale economies at the local level can be quite substantial. These imply that all retail trade tends to tip between two very different systems of distribution. One is of small, higher-service stores spaced close together. The other is of larger, low-service stores spaced farther apart. In this paper, these two equilibria show up as low productivity and high productivity, respectively. Yet Victor Fuchs, writing thirty years ago about the supermarket, noted that the productivity gains come, quite literally, from putting the customer to work. ${ }^{3}$

It is too soon to say that the replacement of one form of retail trade with another in the United States was an unmixed blessing. It happened many years ago in food distribution. Small stores to which most people walked were replaced with larger ones to which most people drove. And this technology of retail trade has diffused slowly across the sector, with Toys ' $R$ ' Us changing one category nearly forty years ago and Home Depot changing another more recently. Do we capture all the costs and benefits of these changes - which have not yet occurred in most other rich economies - by just looking at productivity in the store itself?

There are systematic changes in the amount of effort retail trade asks of the customer. As the stores get bigger, cheaper, and farther apart, the customers have to work harder both to get to the stores and as they shop. This is probably not a reason to conclude that the United States has a worse retail trade sector than other countries. But it is a good reason to remember that productivity is not welfare. If regulatory or policy conclusions are going to be made from an analysis, I would be in favor of putting both the costs and benefits of the policy in quantitative terms.

Economics is often accused of being the unthinking instrument of the political right. Economists are very good at quantifying the benefits of competition-productivity, efficiencies, and so forth-but tend, as this paper does, to leave the costs in terms of quality or whatever in vague, qualitative terms. Thus, economists offer hard facts and data about the things the political right cares about, and then " Gee, it is just 
too hard to quantify" all the things the political left thinks are decisive on the issues.

Let me extrapolate from these two industry examples to why I think that the two papers inside this one, the one on industry productivity comparison, and the other on competition and regulatory policy, appear to me so unrelated. The analysis starts from a true statement: anything policy can do to make living standards grow an extra half percent a year faster will swamp a great many static welfare triangles. It was only a small mistake to get from that observation to "only productivity matters," and then only another small mistake to get to "we should measure productivity to decide how well economies are doing", in service industries. These two small logical mistakes, taken together, come to a big gap, it seems to me, between the question at hand about regulatory policy's effect on competition and the answer offered in the tables.

But that said, let me also say that the opening of the question about the long-run effects of competition within industries is a valuable accomplishment for Martin Baily. It might be true that competitive institutions have a first-order effect through the selection mechanism. They might therefore contribute to long-run growth through new goods, new firms, and new forms of firm organization. The flexibility competitive institutions allow in moving to new forms may well turn out to be an important part of the long-run story.

General Discussion: Several participants proposed additional research to test the author's hypothesis on the negative effects of regulation on productivity. Noting that three of the four U.S. industries examined in the paper had been more extensively regulated in the recent past than they are now, George Borts suggested comparing the productivity levels of these industries at the time they were regulated. Michael Katz argued that different regulations are concerned with very different matters, such as collective bargaining rights, pricing, employment, and government procurement. He said that the author needs to disentangle the effects of these different types of regulations. Noting that regulatory treatment is likely to vary within an industry based on submarketssuch as cellular communications, local exchange services, and network services in telecommunications-he suggested that cross-sectional 
work within industries in a given country may be one way to do this. Katz also suggested doing time series work on the effects of deregulation by looking at either the U.S. or British telecommunications industry. Henry Ergas suggested looking at deregulation in other countries, such as New Zealand and Australia.

Methodological and measurement issues were also a focus of considerable discussion. Ergas noted that the author's explanation of productivity differentials in telecommunications rests heavily on traffic differences among the different systems. He pointed out that the greatest difference between telecommunications in the United States and other countries is in local traffic per access line. He argued that because the results also show that local traffic is very price inelastic, price differences cannot be used to explain the demand differences. Ergas went on to suggest, however, that the European and Japanese telecommunications industries carry a lot of excess labor.

John Pencavel questioned the author's extensive use of labor productivity as the measure of productivity. He noted that his own work comparing worker-owned firms to conventional firms shows that the former have considerably lower rates of labor productivity but higher rates of capital and material productivity than do the latter. Arguing that worker-owned firms are similar to nationalized and heavily regulated European firms because the latter two are often forced by governments to be concerned explicitly with the welfare of workers, he suggested that in those European firms, low labor productivity may coexist with high capital and material factor productivity. This would mean, Pencavel said, that the author is biasing his results by looking only at labor productivity.

Ernst Berndt suggested that one of the most important changes in retail trade in the last decade or so has been the expansion of mail order operations, which he suspected were not included in the retail trade data used in the paper. Because mail order represents a higher proportion of total retail trade in the United States than it does in Europe and Japan, the paper is probably understating the U.S. productivity advantage in the retail sector.

Robert Hall argued that because the author's model does not consider material input, outsourcing of work - such as an airline hiring another company to take care of its baggage handling or maintenance-is not 
accounted for properly. As a result, Hall maintained, measured productivity rises with increased outsourcing, making the paper's productivity estimations suspect.

Michelle White argued that regulation is often used to foster job stability. She said that the paper's results could be interpreted as showing that the Europeans and Japanese are more concerned with such stability than Americans are and, consequently, are willing to accept a loss in income in return for job stability. If this were the case, White said, productivity convergence should never be expected to occur.

Frank Wolak suggested that capital and intermediate input quality might provide an additional explanation for the differences in productivity levels observed by the author. Citing such examples as checkclearing machines and ATMs in banking, automated operators in telecommunications, and optical scanners in retailing, he argued that the diffusion of new technologies is more rapid in service industries in the United States than in other countries, resulting in higher average input quality in the United States.

Ergas took issue with two of the points Timothy Bresnahan made during his discussion of the paper. First, he disagreed with Bresnahan's claim that the Japanese telecommunications industry is characterized by consumer subsidization of business. Instead, Ergas argued that subsidies move from business to consumers, just as in the United States. Second, he questioned Bresnahan's claim that the structural change in retailing that has led to a trend toward larger, self-service stores may have had a negative effect on consumer welfare by forcing shoppers to travel farther to stores and, concomitantly, to exert more effort in these stores. Ergas argued that consumers have, in effect, voted with their feet in choosing these larger stores, that is, the trend toward larger, self-services stores reflects customers' valuation of the relative costs and benefits of this new mode of shopping.

Author's Response: Martin Baily disagreed with some of Robert Gordon's comments. Gordon asserts that the development of hub and spoke preceded deregulation, Baily observed, but then Gordon himself notes that before deregulation, existing hubs "were missing spokes (due to route regulations ... .)." Baily also suggested that Gordon had misunderstood the argument about hub and spoke. The paper asserts only that the U.S. hub and spoke system did not give U.S. airlines a productivity 
advantage. Gordon points out that Southwest Airlines has advantages in the U.S. market compared with the major U.S. airlines. This seems to support the main thesis of the paper, rather than undermining it. The major airlines are burdened with salaries and work rules that still show some residual effects from the era when U.S. airlines were regulated. 


\section{References}

Abe, Yoshibumi. 1991. "Retail: Deregulation Spurs Drastic Changes in Retail Industry Structure.' Japan Economic Almanac. Tokyo: Nikkei Weekly.

Achabel, Dale A., John M. Heineke, and Shelby H. McIntyre. 1984. "Issues and Perspectives on Retail Productivity.' Journal of Retailing 60 (3, Fall): 102-27.

$\rightarrow$ Ando, Albert, and Alan J. Auerbach. 1990. "The Cost of Capital in Japan: Recent Evidence and Further Results." Journal of the Japanese and International Economies 4 (December): 323-50.

Bailey, Elizabeth E., David R. Graham, and Daniel P. Kaplan. 1985. Deregulating the Airlines. Cambridge, Mass.: MIT Press.

$\rightarrow$ Baily, Martin Neil, and Robert J. Gordon. 1988. "The Productivity Slowdown, Measurement Issues, and the Explosion of Computer Power." Brookings Papers on Economic Activity 2:347-431.

$\rightarrow$ Baltensperger, Ernst. 1972. "Economies of Scale, Firm Size, and Concentration in Banking." Journal of Money, Credit, and Banking 4 (August): 46788.

$\rightarrow$ Baltensperger, Ernst, and Jean Dermine. 1987. "Banking Deregulation in Europe." Economic Policy 4 (April): 63-109.

Baumol, William J., Sue Anne Batey Blackman, and Edward N. Wolff. 1989. Productivity and American Leadership: The Long View. Cambridge, Mass.: MIT Press.

Beckman, Theodore N. 1957. "The Value Added Concept as a Measure of Output." Advanced Management 22 (April): 6-9.

Berger, Allen N., and David B. Humphrey. 1992. "Measurement and Efficiency Issues in Commercial Banking."' In Griliches (1992).

Bernheim, B. Douglas, and John B. Shoven. 1987. "Taxation and the Cost of Capital: An International Comaprison." In Charls E. Walker and Mark A. Bloomfield, eds. The Consumption Tax: A Better Alternative? Cambridge, Mass.: Ballinger.

Bertin, Amy, Timothy F. Bresnahan, and Daniel M. G. Raff. 1992. “Aggregation, Localized Competition, and Plant-Level Short-Run Increasing Returns: Blast Furnace Operations 1929-1935."' Research Paper 303. Center for Economic Policy Research, Stanford University, Stanford, California.

Betancourt, Roger. 1992. "An Analysis of the U.S. Distribution System." Working Paper 92-6. Department of Economics, University of Maryland, College Park.

Bolter, Walter G., James W. McConnaughey, and Fred J. Kelsey. 1990. Telecommunications Policy for the 1990s and Beyond. Armonk, N.Y.: M. E. Sharpe, Inc.

Borrus, Michael, François Bar, Patrick Cogez, Anne Brit Thoreson, Ibrahim 
Warde, and Akihiro Yoshikawa. 1985. "Telecommunications Development in Comparative Perspective: The New Telecommunications in Europe, Japan, and the U.S.' Berkeley Roundtable on the International Economy (May).

Bortnick, Jane. 1983. “International Telecommunications and Information Policy: Selected Issues for the 1980's.' A Report Prepared for the Committee on Foreign Relations, U.S. Senate. Congressional Research Service. September.

$\rightarrow$ Bresnahan, Timothy F. 1986. "Measuring the Spillovers from Technical Advance: Mainframe Computers in Financial Services." American Economic Review 76 (September): 742-55.

Bröker, G. 1989. Competition In Banking. Paris: OECD.

Brown, Anthony E. 1987. The Politics of Airline Deregulation. Knoxville: University of Tennessee Press.

Cary, John L., and Phyllis Flohr Otto. 1977. “'Output per Unit of Labor Input in the Retail Food Store Industry." Monthly Labor Review 100 (January): 42-47.

Caves, Douglas W., Laurits R. Christensen, Michael W. Tretheway, and Robert J. Windle. 1987. "An Assessment of the Efficiency Effects of U.S. Airline Deregulation via an International Comparison." In Bailey, Elizabeth E., ed. Public Regulation: New Perspectives on Institutions and Policies. Cambridge, Mass.: MIT Press.

Clark, Jeffrey A. 1988. "Economies of Scale and Scope at Depository Financial Institutions: A Review of the Literature." Economic Review. Federal Reserve Bank of Kansas City. 73 (September/October): 16-33.

Commission of the European Communities. 1988. "The Economics of 1992." European Economy 35 (March).

Crandall, Robert W. 1991. After the Breakup: U.S. Telecommunications in a More Competitive Era. Washington, D.C.: Brookings.

Crandall, Robert W., and Kenneth Flamm, eds. 1989. Changing the Rules: Technological Change, International Competition, and Regulation in Communications. Washington, D.C.: Brookings.

Cumming, Christine M., and Lawrence M. Sweet. 1987. "Financial Structure of the G-10 Countries: How Does the United States Compare?" Federal Reserve Bank of New York Quarterly Review 12 (Winter): 14-25.

Dale, Richard. 1982. Bank Supervision around the World. New York: Group of Thirty.

- 1984. The Regulation of International Banking. Cambridge, Mass.: Woodhead-Faulkner.

Davidson, William H., Ronald Hubert, and Edward St. Croix. 1993. "Telecommunications Infrastructure Policy and Performance: A Global Perspec- 
tive." Center for Telecommunications Management, University of Southern California. January.

$\rightarrow$ De Long, J. Bradford, and Lawrence H. Summers. 1991. "Equipment Investment and Economic Growth." Quarterly Journal of Economics 106 (May): 445-502.

Denison, Edward F. 1962. The Sources of Economic Growth in the United States. New York: Committee for Economic Development.

- 1972. "Some Major Issues in Productivity Analysis: An Examination of Estimates by Jorgenson and Griliches." Survey of Current Business (May): 37-63.

- 1985. Trends in American Economic Growth, 1929-1982. Washington, D.C.: Brookings.

Dodwell Marketing Consultants. 1991. Retail Distribution in Japan. 4th ed. Tokyo.

Dziobek, Claudia. 1992. “The German Banking System and Recent Financial Market Reforms." Paper presented at the Brookings Institution, November 18, and revised December.

The Economist. 1984. "World Airlines: A Survey." August 25, pp. Survey 1-22.

The Economist. 1986. "Europe's Air Cartel: Break it up, But not the American Way." November 1, pp. 23-24.

Ergas, Henry. 1992. "France Telecom: Has the Model Worked?" OECD, Paris.

Ergas, Henry, Eric Ralph, and Siva Sivakumar. 1990. "Reforming Australian Telecommunications: A Review of Issues and Options." Monict Working Paper. Monash University, Clayton, Victoria, Australia.

$\rightarrow$ Evans, William N., and Iaonnis Kessides. 1993. "Structure, Conduct, and Performance in the Deregulated Airline Industry." Southern Economic Journal 59 (3, January): 450-67.

Fixler, Dennis J., and Kimberly D. Zieschang. 1992. "User Costs, Shadow Prices, and the Real Output of Banks.' In Griliches (1992).

Freeman, Richard B., and James L. Medoff 1984. What Do Unions Do? New York: Basic Books.

$\rightarrow$ Friend, Irwin, and Ichiro Tokutsu. 1987. "The Cost of Capital to Corporations in Japan and the USA." Journal of Banking and Finance 11 (June): 31327.

Fuchs, Victor R. 1968. The Service Economy. New York: Columbia University Press.

Gerus, Victoria, and Charles Schott. 1992. "Summary of EC Regulatory Initiatives in the Telecommunications Sector." Memorandum. McKinsey \& Co. New York. 
Good, David H., Lars-Hendrik Roller, and Robin C. Sickles. 1993. "US Airline Deregulation: Implications for European Transport.' Unpublished.

Goodman, Charles S. 1985. "On Output Measures of Retail Performance." Journal of Retailing 61 (3, Fall): 77-82.

Gordon, Robert J. 1992. “Productivity in the Transportation Sector.' In Griliches (1992).

- 1965. "Airline Costs and Managerial Efficiency." In Transportation Economics: A Conference of the Universities-National Bureau Committee for Economic Research. New York: National Bureau of Economic Research.

Griliches, Zvi, ed. 1992. Output Measurement in the Service Sectors. National Bureau of Economic Research Studies in Income and Wealth. Chicago: University of Chicago Press.

Hatsopoulos, George N., and Stephen H. Brooks. 1986. "The Gap in the Cost of Capital: Causes, Effects, and Remedies." In Landau, Ralph, and Dale W. Jorgenson, eds. Technology and Economic Policy. Cambridge, Mass.: Ballinger.

Heffernan, Shelagh A. Forthcoming. "Competition in British Retail Banking." Journal of Financial Services Research.

Hyman, Leonard S., Richard C. Toole, and Rosemary M. Avellis. 1987. The New Telecommunications Industry. vol 1. Arlington, Va.: Public Utilities Reports, Inc.

$\rightarrow$ Ingene, Charles A. 1982. "Labor Productivity in Retailing." Journal of Marketing 46 (Fall): 75-90.

- 1984. "Productivity and Functional Shifting in Spatial Retailing: Private and Social Perspectives.' Journal of Retailing 60 (3, Fall): 15-36.

$\rightarrow$ Jorgenson, Dale W., and Zvi Griliches. 1967. "The Explanation of Productivity Change." Review of Economic Studies 34 (July): 249-83.

Kasper, Daniel M. 1988. Deregulation and Globalization: Liberalizing International Trade in Air Services. Cambridge, Mass.: Ballinger.

Kendrick, John W. 1961. Productivity Trends in the United States. Princeton, N.J.: Princeton University Press.

Kester, W. Carl, and Timothy A. Luehrman. 1992. "The Myth of Japan's Low-Cost Capital." Harvard Business Review 70 (May-June): 130-38.

Maddison, Angus. 1989. The World Economy in the 20th Century. Paris: OECD Development Centre.

McCauley, Robert N., and Steven A. Zimmer. 1989. "Explaining International Differences in the Cost of Capital." Federal Reserve Bank of New York Quarterly Review 14 (Summer): 7-28.

McKinsey Global Institute. 1992. Service Sector Productivity. Washington, D.C.: McKinsey \& Company.

$\rightarrow$ Morrison, Steven A., and Clifford Winston. 1985. "Intercity Transportation 
Route Structures under Deregulation: Some Assessments Motivated by the Airline Experience.' American Economic Review 75 (May): 57-61.

\section{D.C.: Brookings.}

Nambu, Tsuruhiko, Kazuyuki Suzuki, and Tetsushi Honda. 1989. “Deregulation in Japan.' In Crandall and Flamm (1989).

Noll, Roger G., and Frances M. Rosenbluth. Forthcoming. “Telecommunications Policy in Japan and the U.S.: Structure, Process, Outcomes." In Cowhey, Peter, and Matthew D. McCubbins, eds. Policy Making in Japan and the United States. Berkeley: University of California Press.

Noyelle, Thierry, and Thomas M. Stanback, Jr. 1992. "Service Sector Productivity and Innovation, United States and Europe: The Airline Industry." Eisenhower Center for the Conservation of Human Resources and McKinsey Global Institute. May.

O'Conner, William E. 1971. Economic Regulation of the World's Airlines: A Political Analysis. New York: Praeger.

OECD (Organization for Economic Cooperation and Development). 1978. Regulations Affecting International Banking Operations of Banks and NonBanks in France, Germany, the Netherlands, Switzerland, the United Kingdom. Paris.

- 1988. Deregulation and Airline Competition. Paris.

-1992a. Banks under Stress. Paris.

lision? Paris.

OECD Working Party No. 1 of the Economic Policy Committee. 1992. "Structure and Change in Distribution Systems: An Analysis of Seven OECD Member Countries.' Economic Policy Committee, OECD, Paris.

$\rightarrow$ Ofer, Gur. 1973. "Returns to Scale in Retail Trade." Review of Income and Wealth 19 (December): 363-84.

Office of Technology Assessment. U. S. Congress. 1987. International Competition in Services: Banking Building Software Know How. . . . OTA-ITE328. Washington, D.C.: GPO.

Oi, Walter Y. 1992. "Productivity in the Distributive Trades: The Shopper and the Economies of Massed Reserves." In Griliches (1992).

Romer, Paul M. 1987. "Crazy Explanations for the Productivity Slowdown." In Fischer, Stanley, ed. NBER Macroeconomics Annual, 1987. Cambridge, Mass.: MIT Press.

F. M. Scherer. 1980. Industrial Market Structure and Economic Performance. Chicago: Rand McNally.

Sickles, Robin C. 1985. "A Nonlinear Multivariant Error Components Analysis of Technology and Specific Factor Productivity Growth with an Application to the U.S. Airlines.' Econometrics 27 (January): 61-78. 
Smith, A. D., and D. M. W. N. Hitchens. 1985. Productivity in the Distributive Trades: A Comparison of Britain, America, and Germany. New York: Cambridge University Press.

$\rightarrow$ Solow, Robert M. 1957. "Technical Change and the Aggregate Production Function."' Review of Economics and Statistics 39 (August): 312-20.

Straetz, Bob. 1993. "European Community Liberalizes Financial Services Market To Become More Competitive.' Business America 114 (February 8): $2-8$.

Straszheim, Mahlon R. 1969. The International Airline Industry. Washington, D. C.: Brookings.

Taylor, Lester D. 1980. Telecommunications Demand: A Survey and Critique. Cambridge, Mass.: Ballinger.

U.S. Department of Commerce. National Telecommunications and Information Administration. 1991. "The NTIA Infrastructure Report: Telecommunications in the Age of Information." October.

van Ark, Bart. Forthcoming. The Economics of Convergence: A Comparative Analysis of Industrial Productivity since 1950. Aldershot, U.K.: Edward Elgar.

$\rightarrow$ Winston, Clifford. 1993. "Economic Deregulation: Days of Reckoning for Microeconomists." Journal of Economic Literature 31 (September): 126389.

Wyckoff, Andrew W. 1993. "The Impact of Computer Prices on International Comparisons of Labor Productivity." Working paper, OECD Directorate for Science, Technology, and Industry, Paris. November.

Yanagida, Yukio. 1991. "Foreign Investment in Japan: Focus on Joint Ventures." Case study materials for a class at Harvard Law School.

Young, Allan H. 1992. "'Alternative Measures of Change in Real Output and Prices.' Survey of Current Business 72 (April): 32-48.

Ypsilanti, Dimitri, and Robin Mansell. 1987. "Reforming Telecommunications Policy in OECD Countries." OECD Observer 148 (October/November): $18-23$. 